Uma heurística GRASP para o problema de dimensionamento de lotes com múltiplas plantas

Mariá Cristina Vasconcelos Nascimento 



\title{
Uma heurística GRASP para o problema de dimensionamento de lotes com múltiplas plantas
}

\author{
Mariá Cristina Vasconcelos Nascimento
}

Orientadora: Profa. Dra. Franklina Maria Bragion de Toledo

Dissertação apresentada ao Instituto de Ciências Matemáticas e de Computação - ICMC-USP, como parte dos requisitos para obtenção do título de Mestre em Ciências - Ciências de Computação e Matemática Computacional.

"VERSÃO REVISADA APÓS A DEFESA"

Data da Defesa:

$28 / 02 / 2007$

Visto da Orientadora:

USP - São Carlos

Abril $/ 2007$ 



\section{Agradecimentos}

Aos meus pais, pela educação, pelo amor e pela presença em minha vida. São pessoas nas quais tenho admiração e respeito, e que constantemente auxiliam meus caminhos e apóiam minhas decisões.

Ao meu namorado Lucas, por ser uma pessoa tão íntegra e estar sempre do meu lado. Amo seu jeito de ser e espero, no mínimo, retribuir todo o amor e toda felicidade a mim dedicados.

À minha orientadora Franklina, por ser tão presente e amiga, e por guiar os meus passos desde a iniciação científica. Admiro sua dedicação e seu carinho.

Ao meu irmão Neto, pela amizade e pelo apoio durante este período. Agradeço-lhe também pela ajuda com as figuras desta dissertação.

À minha avó Maria, que com seus 93 anos representa um exemplo de vida para mim.

Ao pessoal do Laboratório de Otimização, pela amizade e pela alegria. Em especial, aos professores Marcos Arenales e Maristela dos Santos, pessoas que tenho um carinho especial e respeito.

Aos professores da USP, pelo ensino a mim concedido desde a graduação. Agradeço em especial ao professor Mario de Castro, pela ajuda com os testes estatísticos.

Aos meus colegas de graduação e aos colegas de Barretos, pelo companheirismo.

Aos funcionários da USP, pela dedicação.

À USP, pelo ambiente e pelo suporte técnico.

À FAPESP, pelo apoio financeiro.

À Deus, pela vida. 



\section{Resumo}

O problema de dimensionamento de lotes, objeto desse estudo, considera um ambiente composto por múltiplas plantas independentes, múltiplos itens e múltiplos períodos. O ambiente de produção tem capacidade limitada e as plantas podem produzir os mesmos itens. Cada planta tem uma demanda própria e é permitida a transferência de lotes entre as plantas, o que envolve um certo custo. Este problema tem como caso particular o de dimensionamento de lotes com máquinas paralelas. O objetivo desta dissertação é propor uma heurística baseada na meta-heurística GRASP (Greedy Randomized Adaptive Search Procedures). Além disso, uma estratégia path relinking foi incorporada ao GRASP como uma fase de melhoria do algoritmo. Para verificar a eficiência da heurística proposta, os seus resultados são comparados aos da literatura tanto no caso de máquinas paralelas quanto no de múltiplas plantas. Como resultado, o problema de múltiplas plantas obteve melhores resultados quando comparado aos da heurística da literatura. Com relação ao problema de máquinas paralelas, a heurística proposta se mostrou competitiva.

Palavras-chave: GRASP, path relinking, dimensionamento de lotes, múltiplas plantas, máquinas paralelas e otimização combinatória. 



\section{Abstract}

The lot sizing problem, which is the aim of this study, considers an environment consisting of multiple independent plants, multiple items and multiple periods. The production environment has limited capacity and the plants can produce the same items. Each plant has its own demand and the lot transfers between the plants are permitted, which involves a certain cost. This problem has as a particular case the parallel machines lot sizing problem. The objective of this dissertation is to propose a heuristic based on the GRASP (Greedy Randomized Adaptive Search Procedures). Furthermore, a path relinking phase is embedded in the GRASP to obtain better performance. To verify the efficiency of the proposed heuristic, its results were compared with the literature as for the multi-plant as for parallel machines problem. Computational tests showed that the proposed heuristic performed better than other literature heuristic concerning the multiplant problem. Concerning the parallel machines, the heuristic is competitive.

Keywords: GRASP, path relinking, lot sizing, multi-plant, parallel machines and combinatorial optimization. 



\section{Índice}

Lista de Figuras $\quad$ ix

Lista de Tabelas $\quad$ xi

1 Introdução 1

2 Revisão Bibliográfica 3

2.1 O problema de dimensionamento de lotes . . . . . . . . . . . . . 3

2.2 Características e classificações do problema . . . . . . . . . . . . . . 4

2.3 Problemas com um único item . . . . . . . . . . . . . . . . . . . . 6

2.4 Problemas com múltiplos itens . . . . . . . . . . . . . . . . . . . 8

2.4 .1 Algoritmos exatos . . . . . . . . . . . . . . . . . 9

2.4 .2 Heurísticas . . . . . . . . . . . . . . . . . . 10

2.5 Problemas com máquinas paralelas . . . . . . . . . . . . . . . 11

2.6 Problemas com múltiplas plantas e múltiplos períodos . . . . . . . . . . . . 12

2.7 Complexidade . . . . . . . . . . . . . . . . . . . . 13

3 Estudo do problema $\quad 15$

3.1 CLSP com múltiplas plantas . . . . . . . . . . . . . . . . . . . 15

3.2 Estudo do problema não capacitado . . . . . . . . . . . . . . . . 18

4 Abordagem ótima do problema $\quad 19$

4.1 Método Branch-and-bound . . . . . . . . . . . . . . . . . . 20

4.2 Primeira etapa de testes . . . . . . . . . . . . . . . . . . . 22

4.2 .1 Experimento $1 \ldots \ldots \ldots \ldots$

4.2 .2 Experimento $2 \ldots \ldots \ldots \ldots \ldots$

4.3 Segunda etapa de testes . . . . . . . . . . . . . . . 26 
5 Método de Solução $\quad 29$

5.1 Meta-heurística GRASP . . . . . . . . . . . . . . . . 30

5.2 Busca Local . . . . . . . . . . . . . . . . . . . . . . . 31

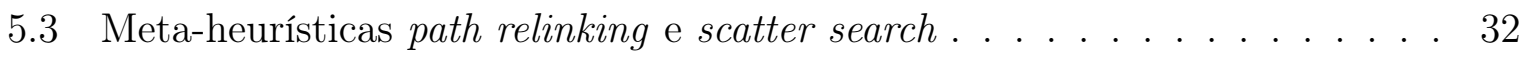

5.4 Heurística proposta . . . . . . . . . . . . . . . . 36

5.4 .1 Solução inicial . . . . . . . . . . . . . . . . . . . . 36

5.4 .2 Vizinhança da Busca . . . . . . . . . . . . . . . . . 38

5.4.3 Estratégia path relinking proposta . . . . . . . . . . . . . . 42

6 Testes computacionais $\quad 43$

6.1 Testes com múltiplas plantas . . . . . . . . . . . . . . . . . . . 44

6.1.1 Experimento 1 . . . . . . . . . . . . . . . 44

6.1 .2 Experimento $2 \ldots \ldots \ldots \ldots$. . . . . . . . . . . . . 47

6.2 Testes com máquinas paralelas . . . . . . . . . . . . . . . . . . . . . . 49

6.2.1 Configuração das instâncias . . . . . . . . . . . . . . . . . . 49

6.3 Análise Estatística . . . . . . . . . . . . . . . . . . . . . . 51

7 Conclusões e Pesquisas Futuras $\quad 55$

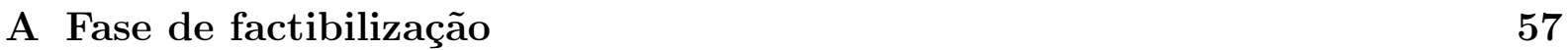

A.1 Descrição . . . . . . . . . . . . . . . . . . . . . 57

$\begin{array}{ll}\text { B Testes estatísticos } & 61\end{array}$

$\begin{array}{ll}\text { Referências Bibliográficas } & 63\end{array}$ 


\section{Lista de Figuras}

2.1 Classificação dos problemas de dimensionamento de lotes. . . . . . . . . . . 5

2.2 Exemplo de rede para um problema com três períodos. . . . . . . . . . 7

4.1 Árvore da partição. . . . . . . . . . . . . . . . . . . . 21

5.1 Exemplo de path relinking. . . . . . . . . . . . . . . . . . 34 



\section{Lista de Tabelas}

4.1 Soluções do Grupo 1 no Experimento 1. . . . . . . . . . . . . . . . . . 23

4.2 Soluções do Grupo 2 no Experimento 1. . . . . . . . . . . . . . . . . . 24

4.3 Soluções do Grupo 1 no Experimento 2. . . . . . . . . . . . . . . . . . . 25

4.4 Soluções do Grupo 2 no Experimento 2. . . . . . . . . . . . . . . . 25

4.5 Testes realizados para outras instâncias. . . . . . . . . . . . 27

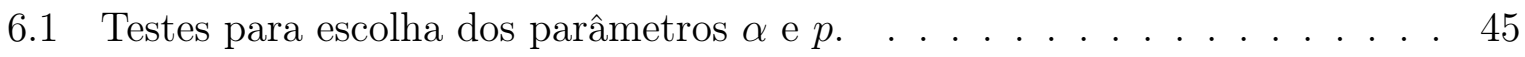

6.2 Resultados do Experimento 1. . . . . . . . . . . . . . . . . 46

6.3 Resultados do Experimento 2. . . . . . . . . . . . . . . . . . . . . . . 48

6.4 Resultados para o CLSP com máquinas paralelas. . . . . . . . . . . . . . . 50

6.5 Resultados estatísticos para múltiplas plantas. . . . . . . . . . . . . . . 52

6.6 Resultados estatísticos para máquinas paralelas. . . . . . . . . . . . . 53

B.1 Resultados estatísticos de múltiplas plantas para os gaps médios. . . . . . . 61

B.2 Resultados estatísticos de máquinas paralelas para os gaps médios. . . . . . 62

B.3 Resultados estatísticos de máquinas paralelas para os tempos médios. . . . 62 



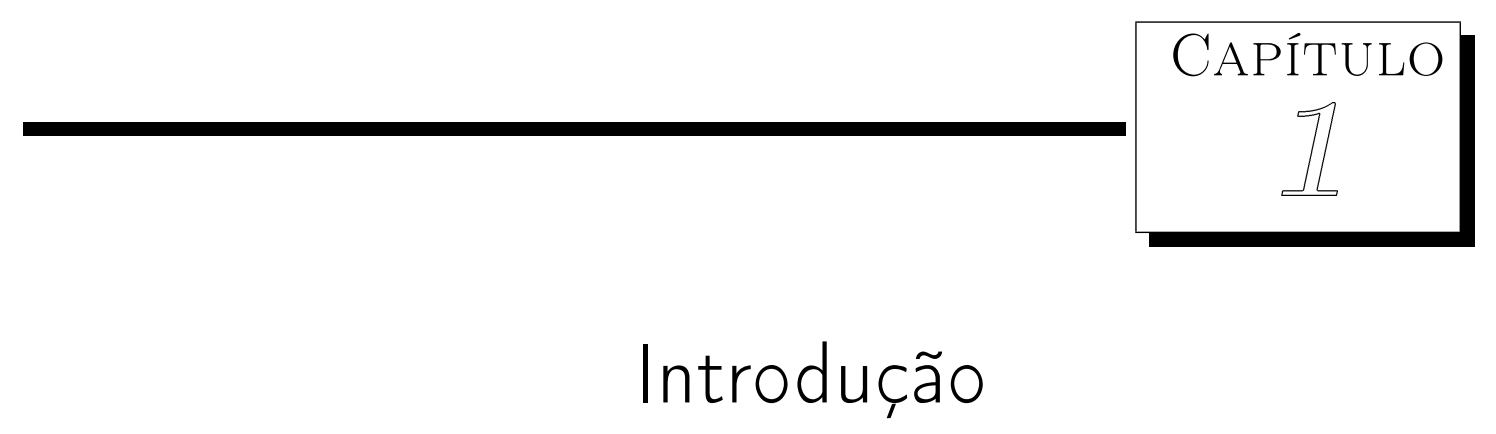

A economia nas últimas décadas foi marcada como um período de expansão e globalização dos mercados, o que levou a um aumento significativo de competitividade entre as empresas. Estes fatos geram a necessidade de um estudo das condições das empresas e um planejamento adequado para que se cumpram seus objetivos. O planejamento de produção surge como objeto de alta relevância para as empresas, neste ambiente competitivo.

O planejamento da produção visa decidir a melhor forma para utilização dos recursos disponíveis por uma empresa para que seus objetivos de longo, de médio e de curto prazo sejam atingidos. As decisões de longo prazos pertencem ao nível estratégico, quando são definidas as metas globais da empresa. O planejamento tático é responsável pela utilização eficiente dos recursos disponíveis, a fim de cumprir os objetivos determinados no planejamento estratégico. Nesta etapa, devem ser tomadas as decisões de médio prazo. O último nível de planejamento é o operacional, que está relacionado ao dia-a-dia da empresa, quando são tomadas as decisões de curto prazo.

Este estudo enfoca o problema de dimensionamento de lotes (PDL) que consiste na determinação de quanto, quando e onde produzir certos itens. Tal tipo de problema se enquadra no planejamento tático da produção. O problema de dimensionamento de lotes, objeto de estudo desta pesquisa, foi inspirado no trabalho de Sambasivan e Yahya (2005) e é composto por múltiplas plantas, por múltiplos itens e por múltiplos períodos. As plantas são independentes e todas produzem os mesmos itens, além de haver a possibilidade de transferência de produção de uma planta para outra. Este problema pode ser encontrado no Brasil em vários setores, em especial, é característico de grandes companhias, que são 
compostas por várias plantas localizadas em diferentes pontos do país, como por exemplo, indústrias de aço laminado, bebidas, colchões, entre outras.

O problema de dimensionamento de lotes com máquinas paralelas é um subproblema do problema de dimensionamento de lotes com múltiplas plantas. Tal problema consiste de um ambiente de produção composto por múltiplas máquinas que produzam todas os mesmos itens. A diferença deste problema para o PDL com múltiplas plantas é a presença de uma única fábrica para produzir e um único armazém para estocar os itens, características tais que acarretam a ausência de custos de se estocar em diferentes áreas.

O objetivo desta dissertação é desenvolver uma meta-heurística GRASP (Greedy Randomized Adaptive Search Procedures) para o problema estudado. Além disso, à metaheurística GRASP é incorporado um método de solução baseado no algoritmo de path relinking visando a melhoria do método de solução proposto. Para compor a metaheurística, utiliza-se um algoritmo de custo mínimo para máquinas paralelas na geração das soluções iniciais e, em seguida, transferências de produção são realizadas entre os períodos e plantas em busca de soluções factíveis e melhores. O algoritmo de path relinking combina as melhores soluções obtidas pelo algoritmo GRASP proposto. Para verificar a eficiência desta heurística, os resultados de máquinas paralelas e múltiplas plantas serão comparados aos da literatura.

Esta dissertação está organizada da seguinte forma: o Capítulo 2 apresenta a revisão bibliográfica dos problemas de dimensionamento de lotes; o Capítulo 3 reporta o estudo do problema de dimensionamento com múltiplas plantas; o Capítulo 4 mostra testes no CPLEX 7.5 usando instâncias do PDL com múltiplas plantas; o Capítulo 5 apresenta o método de solução abordado descrevendo a meta-heurística proposta nesta dissertação; no Capítulo 6 a configuração das instâncias é apresentada e os resultados dos testes computacionais são reportados; e por fim, no Capítulo 7, são apresentadas as conclusões e pesquisas futuras. 


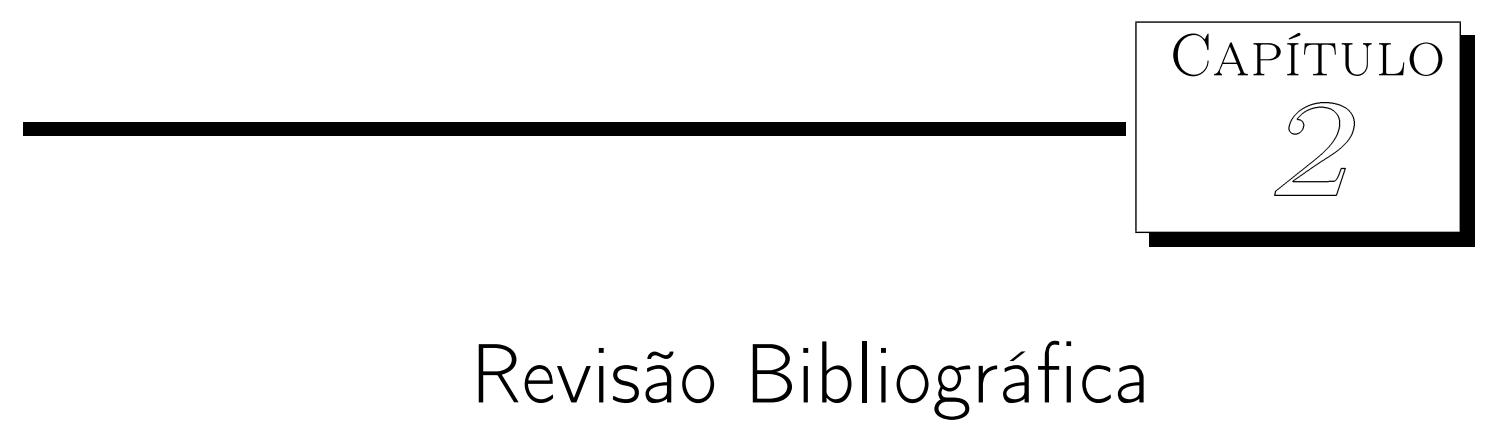

\subsection{O problema de dimensionamento de lotes}

O problema de dimensionamento de lotes (PDL) envolve a determinação do quanto produzir de um determinado item em cada um dos períodos de um horizonte de planejamento finito. O objetivo é encontrar um plano de produção de mínimo custo capaz de atender à demanda dos produtos sem violar a capacidade de produção disponível.

Uma característica importante que tem motivado os pesquisadores a estudar os problemas de dimensionamento de lotes é a quantidade de variações existentes para o mesmo. Dado o grande número de decisões a serem tomadas na solução de problemas reais, esses, na maioria das vezes, são intratáveis.

Como existem poucos artigos que estudam especificamente o problema de dimensionamento de lotes com múltiplas plantas, esta revisão bibliográfica tem como objetivo o conhecimento geral do PDL e de algumas de suas variações, para que estes dêem suporte ao estudo mais detalhado do problema abordado neste trabalho.

A literatura destinada ao problema de dimensionamento de lotes é bastante rica e boas revisões podem ser encontradas em Karimi et al. (2003), Drexl e Kimms (1997), Wolsey (1995), Kuik et al. (1994), Bahl et al. (1987) e Brahimi et al. (2006). 


\subsection{Características e classificações do problema}

Devido à variedade de problemas de dimensionamento de lotes, surge a necessidade de caracterizar e classificar o problema para assim facilitar o estudo de seus diferentes tipos. Karimi et al. (2003) apresentam e discutem as principais características do problema de dimensionamento de lotes, e afirmam que, além de ser um dos problemas mais importantes, é também um dos mais difíceis no planejamento de produção. Tais características foram resumidas e são apresentadas a seguir.

Horizonte de planejamento - É o limitante superior de tempo em que a produção deve ser planejada. Este pode ser definido como finito ou infinito. Além disso, o horizonte de planejamento pode ser dividido em períodos grandes, "big buckets", o que possibilita a produção de vários itens num mesmo período, e em pequenos períodos, "small buckets", cujo tempo de produção é curto, resultando na produção de um único item por período. Um tipo de horizonte de planejamento é o horizonte rolante, que é usado quando há incerteza dos dados, como por exemplo, variações constantes na carteira de pedido dos itens.

Número de níveis - O problema de dimensionamento de lotes pode ter um único estágio (monoestágio) ou múltiplos estágios de planejamento. Um sistema tem um único estágio quando um item não depende de outro para ser produzido. Nos sistemas com múltiplos estágios, um item final possui itens componentes, cuja produção ou compra também devem ser planejadas.

Número de produtos - Existem dois tipos principais de problemas que caracterizam o sistema de produção: único item e múltiplos itens. O primeiro considera somente um tipo de item no sistema de produção, enquanto o último considera mais tipos de itens finais.

Capacidade de recursos - A capacidade de recursos é um fator limitante da produção. Se o problema não tiver limite de capacidade, o problema é dito sem capacidade, ou não capacitado. Caso contrário, é denominado capacitado.

Demanda - É o quanto deve ser produzido para atender aos pedidos. Para este parâmetro, existem duas variantes: a demanda dinâmica, que muda com o tempo, e a estática, que não se modifica. Caso seja conhecido o valor da demanda "a priori", tem-se a demanda determinística, caso contrário, tem-se a probabilidade da demanda, ou seja, a demanda é estocástica.

Estrutura da preparação para produção (setup) - A preparação para produção existe quando a mudança de produção para diferentes produtos acarreta em um custo de preparação e/ou um tempo de preparação. Além disso, há duas classes de preparação: a 
preparação independente, ou seja, são independentes de períodos ou itens anteriores; e a preparação dependente, que ocorre quando há uma dependência seqüencial de períodos ou itens anteriores.

Bahl et al. (1987) restringiram a classificação dos problemas a duas características principais: estágios de produção e restrições de capacidade. A Figura 2.1 ilustra este tipo de classificação.

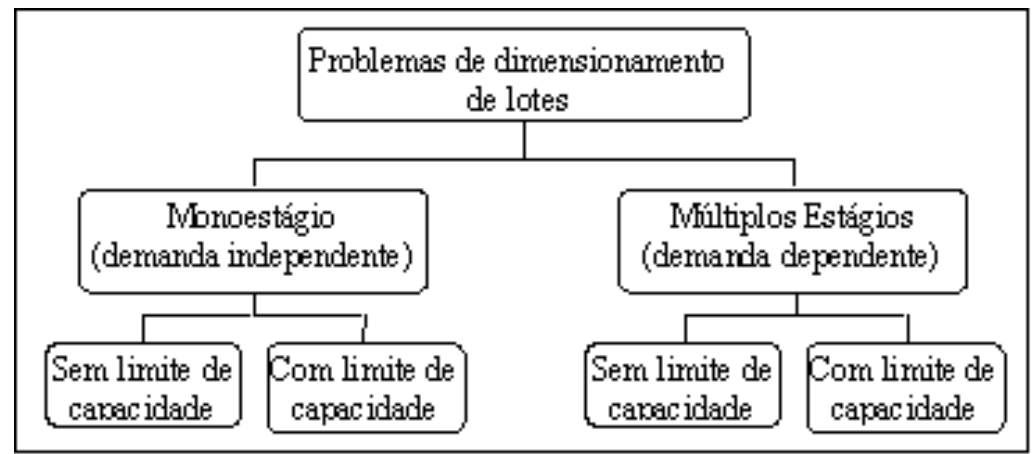

Figura 2.1: Classificação dos problemas de dimensionamento de lotes.

Drexl e Kimms (1997) apresentam o problema de dimensionamento de lotes e scheduling na organização do sistema produtivo de uma empresa. Apresentam as diferenças de modelos formais, com ênfase no problema capacitado, dinâmico e determinístico, e fornecem várias recomendações de leitura. Além disso, apresentam a divisão dos problemas em seis grandes grupos:

Economic lot scheduling problem (ELSP) - Este problema é caracterizado por ter um único nível, múltiplos itens, demanda estática e plano de horizonte infinito. Além disso, ele é contínuo, ou seja, não há a divisão do horizonte de planejamento em períodos.

Os próximos modelos apresentados são caracterizados pelo horizonte de planejamento finito.

Capacited lot sizing problem (CLSP) - É um problema de dimensionamento de lotes capacitado com único ou múltiplos itens. Neste problema, vários itens podem ser produzidos por período. Este problema é caracterizado por períodos longos, "big buckets".

Discrete lot sizing and scheduling problem (DLSP) - É um problema que adota a política "tudo ou nada", pois somente um item pode ser produzido em cada período e este deve ocupar toda a sua capacidade. Ao contrário do CLSP, este tipo de problema é caracterizado por períodos curtos, "small buckets".

Continuous setup lot sizing problem (CSLP) - Este problema é semelhante ao DLSP, pois apenas um item pode ser produzido a cada período, entretanto, não é regra a utilização 
total da capacidade dos períodos.

Proporcional lot sizing and scheduling problem (PLSP) - O PLSP, por sua vez, é semelhante ao CSLP. Ele difere do CSLP por permitir a utilização da sobra de capacidade do período, ou seja, um segundo item pode ocupar o restante da capacidade do período.

General lot sizing and scheduling problem (GLSP) - É um problema de dimensionamento e seqüenciamento de lotes capacitado com múltiplos itens.

Nesta dissertação, é apresentada uma revisão bibliográfica sobre o problema de dimensionamento de lotes em que são enfatizados os trabalhos que abordam problemas com único estágio, pois este é o enfoque do problema estudado.

\subsection{Problemas com um único item}

Em Wolsey (1995) e Brahimi et al. (2006), os autores apresentam uma revisão de trabalhos que abordam o problema de dimensionamento de lotes com um único item (PDLUI). Em ambas as revisões, uma motivação discutida para o estudo desta classe de problemas é o número de métodos de solução do problema de dimensionamento de lotes com múltiplos itens que tem como subproblemas PDLUI's capacitados que, por sua vez, são resolvidos de forma aproximada por subproblemas de único item não capacitados.

O PDLUI não capacitado pode ser representado pelo modelo a seguir.

$$
\min \sum_{t=1}^{T}\left[c_{t} x_{t}+s_{t} y_{t}+h_{t} I_{t}\right]
$$

sujeito a:

$$
\begin{array}{ll}
I_{t-1}+x_{t}-I_{t}=d_{t} & t=1, \ldots, T \\
x_{t} \leq \sum_{k=t}^{T} d_{k} y_{t} & t=1, \ldots, T \\
I_{0}=0 & \\
x_{t}, I_{t} \geq 0 & t=1, \ldots, T \\
y_{t} \in\{0,1\} & t=1, \ldots, T
\end{array}
$$

em que:

$T$ : é o número de períodos do horizonte de planejamento (parâmetro);

$d_{t}$ : demanda do item no período $t$ (parâmetro);

$c_{t}$ : custo de produção do item no período $t$ (parâmetro);

$s_{t}:$ custo de preparação para produção do item no período $t$ (parâmetro);

$h_{t}$ : custo de estocagem do item no período $t$ (parâmetro); 
$x_{t}$ : quantidade produzida do item durante o período $t$ (variável);

$I_{t}$ : quantidade em estoque do item no final do período $t$ (variável);

$y_{t}$ : variável binária que assume o valor 1 , caso haja a produção do item no período $t$, e 0, caso contrário (variável).

O objetivo deste problema é determinar um plano de produção para o item de forma que atenda às restrições de demanda sem atraso, procurando minimizar a soma dos custos de preparação, de produção e de estoque.

O primeiro algoritmo exato para a resolução do PDLUI não capacitado foi um algoritmo de programação dinâmica apresentado por Wagner e Whitin (1958) de ordem $O\left(T^{2}\right)$. O algoritmo proposto consiste em encontrar o caminho de custo mínimo numa rede, cujos nós e arcos representam, respectivamente, os períodos e os custos de produção entre os períodos (ver Figura 2.2). O custo de produção entre o nó $k$ e o nó $t$, com $k<t$ é a soma do custo de preparação no período $k+1$, do custo de produção da soma das demandas do período $k+1$ ao período $t$ e do custo de estoque das demandas do período $k+2$ ao período $t$, ou seja, é dado por:

$$
M_{k t}=s_{k+1}+c_{k+1} \sum_{j=k+1}^{t} d_{j}+\sum_{j=k+2}^{t-1} h_{j} \sum_{i=j+1}^{t} d_{i}
$$

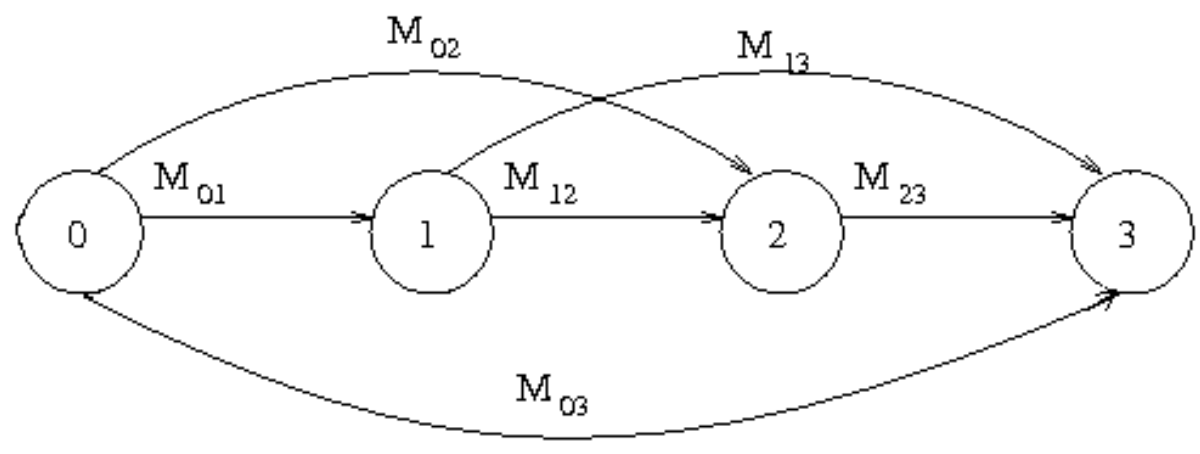

Figura 2.2: Exemplo de rede para um problema com três períodos.

O Algoritmo 1 é um resumo do algoritmo de Wagner e Whitin (1958). O custo mínimo de produção até o período $t$ é representado por $F_{t}$ que é a soma do custo mínimo de produção até o período $t^{\prime}\left(F_{t^{\prime}}\right)$ mais o custo de produção de $t^{\prime}$ até o período $t\left(M_{t^{\prime}, t}\right)$. Seja, no Algoritmo 1, Leia Entrada() a função responsável pela leitura de dados do problema.

Há pouco mais de dez anos, a complexidade do algoritmo de programação dinâmica para este problema foi reduzida para $O(T \log T)$ por diferentes grupos de pesquisadores, 


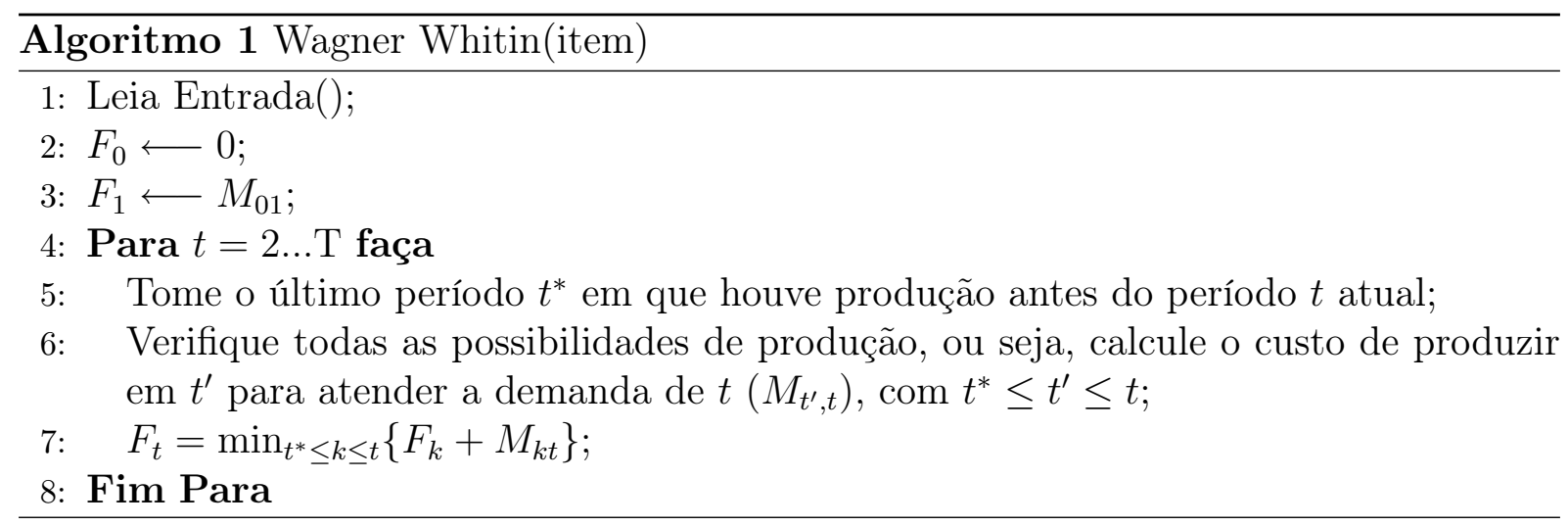

Aggarwal e Park (1993), Federgruen e Tzur (1991), Wagelmans et al. (1992).

O modelo do problema capacitado com único item é semelhante ao não capacitado, com a adição das restrições de capacidade: $b_{t} x_{t} \leq C_{t}$ com $t=1, \ldots, T$, onde $b_{t}$ é o tempo de produção da unidade do item e $C_{t}$ é a capacidade da máquina no período $t$. Segundo Fleischmann (1990), os métodos de solução para o problema capacitado são, na maioria, métodos baseados em programação inteira e nas características do espaço solução do problema estudado.

\subsection{Problemas com múltiplos itens}

O problema de dimensionamento de lotes com múltiplos itens (PDLMI) é bastante explorado na literatura. Isto é decorrente do maior número de aplicações em situações reais e ainda, à variedade de problemas conhecidos.

A primeira classe de problemas a ser destacada é o PDLMI não capacitado, que pode ser resolvida na otimalidade pelo algoritmo de Wagner e Whitin (1958). Isto é conseqüência do fato dos modelos matemáticos para o PDLMI não capacitado não apresentarem dependência entre os itens, como pode ser observado a seguir. Logo, se o problema for composto de $N$ itens, ele poderá ser decomposto em $N$ subproblemas de único item, que podem ser resolvidos pelo algoritmo de Wagner e Whitin (1958).

$$
\min \sum_{t=1}^{T} \sum_{i=1}^{N}\left[c_{i t} x_{i t}+s_{i t} y_{i t}+h_{i t} I_{i t}\right]
$$

sujeito a:

$$
\begin{aligned}
& I_{i t-1}+x_{i t}-I_{i t}=d_{i t} \quad i=1, \ldots, N ; \quad t=1, \ldots, T ; \\
& x_{i t} \leq\left(\sum_{k=t}^{T} d_{i k}\right) y_{i t} \quad i=1, \ldots, N ; \quad t=1, \ldots, T ; \\
& I_{i 0}=0 \quad i=1, \ldots, N \text {; } \\
& x_{i t}, I_{i t} \geq 0 \quad i=1, \ldots, N ; \quad t=1, \ldots, T \text {; } \\
& y_{i t} \in\{0,1\} \quad i=1, \ldots, N ; \quad t=1, \ldots, T \text {; }
\end{aligned}
$$


em que:

$T$ : é o número de períodos do horizonte de planejamento;

$N$ : é o número de itens do horizonte de planejamento;

$d_{i t}$ : demanda do produto $i$ no período $t$

$c_{i t}$ : custo de produção do item $i$ no período $t$;

$s_{i t}$ : custo de preparação para produção do item $i$ no período $t$;

$h_{i t}$ : custo de estocagem do item $i$ no período $t$;

$x_{i t}$ : quantidade do item $i$ produzida durante o período $t$ (variável);

$I_{i t}$ : quantidade do item $i$ estocada no final do período $t$ (variável);

$y_{i t}$ : variável binária que assume o valor 1 , caso haja preparação para a produção do item $i$ no período $t$, e 0 , caso contrário (variável).

Quando as restrições de capacidade são acrescentadas, a propriedade de independência dos itens deixa de existir, uma vez que todos compartilham a capacidade de produção do período, o que torna o problema mais complexo. Outra característica importante é o tempo de preparação da produção que, quando considerado, aumenta a dificuldade de solução do problema. Nas pesquisas da década de 80, o tempo de preparação foi considerado insignificante. Entretanto, desconsiderar este parâmetro pode tornar o problema mais distante de situações reais, principalmente quando o problema apresenta capacidade apertada.

Vale observar que apenas pequenas instâncias (com baixo número de itens e períodos) do PDLMI capacitado com tempos de preparação (CLSP) são resolvidas em tempo razoável na otimalidade. Devido à dificuldade destes problemas, poucos métodos ótimos foram propostos para sua solução (Diaby et al. (1992a), Souza e Armentano (1994) e França et al. (1999)). Em quantidade mais expressiva são encontradas as heurísticas, dentre as quais se destacam Trigeiro et al. (1989), Lozano et al. (1991), Diaby et al. (1992b), Sox e Gao (1999) e Gopalakrishnan et al. (2001).

\subsubsection{Algoritmos exatos}

Diaby et al. (1992a) desenvolveram procedimentos branch-and-bound para o CLSP. A geração do limitante inferior é feita por uma relaxação Lagrangiana das restrições de demanda ou de capacidade, e um método do subgradiente é usado para maximizar a função dual correspondente. 
Souza e Armentano (1994) resolvem o CLSP com limitação nas variáveis de produção por um algoritmo ótimo de decomposição cruzada encontrado na literatura.

França et al. (1999) propõem uma representação em redes para o CLSP. O limitante superior é obtido resolvendo o problema linear com as variáveis binárias atribuídas pela solução da heurística proposta por Trigeiro et al. (1989). Em seguida, um método branchand-bound baseado em redes foi aplicado para a solução dos problemas.

\subsubsection{Heurísticas}

Trigeiro et al. (1989) desenvolveram uma heurística Lagrangiana para a resolução do CLSP. A relaxação é feita nas restrições de capacidade, o que faz com que o problema seja decomponível em subproblemas não capacitados, que são resolvidos pelo algoritmo de programação dinâmica de Wagner e Whitin (1958). Os multiplicadores duais são atualizados pelo método do subgradiente. Os autores concluíram com este estudo que, quanto mais "apertada" é a capacidade do problema, mais difícil se torna sua solução, e que o algoritmo desenvolvido resolve melhor problemas grandes do que problemas pequenos.

Lozano et al. (1991) desenvolveram uma heurística para o CLSP usando um método primal-dual para resolver o problema Lagrangiano. O algoritmo tem propriedades de convergência e, de acordo com testes realizados com um grande número de instâncias, foram obtidas boas soluções, tendo em vista o tempo computacional. Um grupo de instâncias dos testes realizados pelos autores apresentou um gap elevado, o que levou a concluir que a heurística não é eficiente para certa classe de problemas.

Diaby et al. (1992a) desenvolveram uma heurística baseada na relaxação Lagrangiana das restrições de capacidade e na otimização por subgradiente com capacidade excedida limitada. Um grande número de exemplos com 5000 itens e 30 períodos foi resolvido. Este procedimento pode ser aplicável em situações reais, devido a sua generalidade e eficiência.

Sox e Gao (1999) desenvolveram uma heurística Lagrangiana para o CLSP com setup carry-over ${ }^{1}$. No modelo apresentado por eles, não foi considerado o tempo de preparação. Segundo os autores, o tempo de preparação pode ser incluído, entretanto, isto exigirá um esforço computacional elevado na execução da heurística. Em testes realizados, eles concluíram que o efeito do setup carry-over é bem significativo para algumas instâncias. Entretanto, deve-se considerar o fato de terem sido usados para os testes apenas 8 problemas de 50 a 100 itens.

\footnotetext{
${ }^{1}$ carry-over consiste na economia do custo de preparação quando o último item produzido num período for o primeiro item a ser produzido no período imediatamente posterior.
} 
Gopalakrishnan et al. (2001) desenvolveram uma heurística de busca tabu para o CLSP com setup carry-over. Os testes foram realizados utilizando instâncias propostas em Trigeiro et al. (1989). Os autores fizeram dois experimentos computacionais. No primeiro, a heurística foi testada sem considerar carry-over e os resultados dos testes foram comparativamente próximos, sendo que em um conjunto de instâncias, a heurística de Gopalakrishnan et al. (2001) obteve um gap médio levemente menor ao de Trigeiro et al. (1989), e em um outro grupo de instâncias, com um número maior de itens e períodos, a heurística de Trigeiro et al. (1989) apresentou-se mais eficiente do que a de Gopalakrishnan et al. (2001). Ao considerar o setup carry-over, os autores geraram limitantes ruins para as instâncias, o que resultou em gaps médios com valores altos. No entanto, em outra análise, os autores mostraram que a economia gerada é significativa quando comparada aos problemas sem carry-over.

\subsection{Problemas com máquinas paralelas}

A literatura fornece poucos estudos de ambientes compostos por máquinas paralelas. Uma heurística para o DLSP composto por máquinas paralelas sem tempo de preparação, em que todas máquinas produzam os mesmos itens, foi proposta por Lasdon e Terjung (1971). Para resolver tal problema, os autores aplicaram um método de geração de colunas.

Sung (1986) apresenta um algoritmo de programação dinâmica para resolver o problema de planejamento de produção de facilidades paralelas com capacidade irrestrita composto por um único item. Baseando-se em tal algoritmo que a solução inicial da heurística proposta nesta dissertação foi construída. Carreno (1990) propõe uma heurística para o ELSP composto por máquinas paralelas que produzem os mesmos itens onde são considerados os tempos de preparação. Tal heurística é baseada na decomposição do problema mencionado em um problema de alocação e um problema de dimensionamento de lotes. A resolução dos dois problemas é feita individualmente, e para certa classe de problemas, a heurística se apresentou eficiente.

Toledo e Armentano (2006) propõem uma heurística baseada na relaxação Lagrangiana das restrições de capacidade e na otimização por subgradiente para o CLSP com máquinas paralelas. Cada passo consiste da factibilização pelo método do subgradiente e da melhoria da solução do problema Lagrangiano. Para isto são executadas transferências de lotes de produção entre os períodos de forma a não violar as restrições de atendimento de demanda. Para testar a heurística foram geradas instâncias compostas por diversas dimensões, apresentadas na Seção 6.2, pois a solução da heurística proposta nesta dissertação foi comparada com estes resultados. 


\subsection{Problemas com múltiplas plantas e múltiplos períodos}

Os problemas com múltiplas plantas compõem uma classe de problemas em que são consideradas várias fábricas, ou plantas, que produzem diversos itens. A solução ótima do problema deve considerar o planejamento da produção integrando as diversas plantas, pois se for tratado um subproblema por planta, a solução ótima do mesmo não é garantida. Além disso, o problema de múltiplas plantas pode ser dividido em dois tipos: o de plantas independentes e o que apresenta dependência entre as plantas.

Bhatnagar et al. (1993) abordam a estrutura de múltiplas plantas dependentes como um sistema complexo com múltiplos estágios. Cada planta representa um sistema de múltiplos estágios cujo fluxo de produtos pode ser em série, em paralelo, conjunto ou geral. As decisões de produção nas plantas devem ser coordenadas para que os objetivos da empresa sejam atingidos. Para isso, devem ser levados em consideração os efeitos da incerteza da demanda final e do processo de produção em cada planta, além das restrições de capacidade de cada planta. O objetivo do problema é coordenar os planos de produção de várias plantas de tal forma que a performance total da empresa seja melhorada. Além disso, os autores julgaram necessário focalizar seu estudo em sistemas capacitados com tempo de preparação, pois estes refletem melhor as situações reais das empresas. Devido à intratabilidade, heurísticas são necessárias para obter boas soluções para este tipo de problema.

Kaminsky e Simchi-Levi (2003) estudam o problema da cadeia produtiva, ou seja, o problema em que os produtos são manufaturados em uma série de facilidades de produção. Eles realizaram o estudo deste modelo em um problema de produção em dois estágios, que leva em consideração o transporte dos produtos entre estes dois estágios de produção, cujo custo atribuído é fixo. Vários algoritmos polinomiais foram apresentados para este modelo com diferentes custos de transporte, linear e não linear. Os autores puderam concluir que o modelo e os algoritmos desenvolvidos servem como ferramentas úteis em situações práticas.

David Wu e Golbasi (2004) apresentam outro algoritmo para a resolução do modelo da cadeia produtiva com múltiplos estágios. Uma heurística baseada em decomposição Lagrangiana é proposta para a solução do problema. Como resultado dos testes, podese concluir que, quando o algoritmo de custo mínimo é usado para um subproblema de único item, o tempo computacional aumenta linearmente com o crescimento do número de facilidades. Por outro lado, quando é resolvido um problema inteiro misto para cada subproblema, o tempo computacional aumenta significativamente.

No caso de plantas independentes, existem propostas de problemas com um ou 
mais estágios de produção. Entretanto, em ambos os tipos, todas as plantas suprem individualmente a produção do item em qualquer número de estágios. Poucos estudos e métodos de solução que tratam explicitamente do problema de dimensionamento de lotes de múltiplas plantas independentes umas das outras foram encontrados.

Sambasivan e Schimidt (2002) propõem uma heurística baseada em transferências de lotes de produção para o CLSP com múltiplas plantas, com múltiplos itens, com múltiplos períodos e com um único estágio de produção, em que as plantas, apesar de serem independentes, podem suprir a demanda de outra por transferência de produção. Além disso, todas as plantas podem produzir todas os mesmos itens. Este é justamente o problema alvo desta dissertação. Na construção da heurística, os autores consideraram o problema não capacitado para gerar soluções iniciais. Há transferências de lotes de produção dentro da planta e entre as plantas nestas soluções iniciais, caso seja necessário, para que estas se tornem factíveis para o problema capacitado. Foram testadas 256 instâncias, geradas de maneira não explícita pelos autores, para verificar a eficiência da heurística comparando sua solução à solução da relaxação linear. A solução obtida pela heurística teve um gap médio de $2.6 \%$, em que o gap foi calculado pela diferença entre a solução obtida pela heurística com a solução do problema relaxado linearmente dividido pela solução relaxada.

Sambasivan e Yahya (2005) apresentam uma heurística baseada na relaxação Lagrangiana para a mesma classe de problemas apresentada no parágrafo anterior. A relaxação Lagrangiana do modelo estudado por Sambasivan e Yahya (2005) foi feita nas restrições de capacidade. De acordo com testes realizados, o número de itens é o fator que causa maior impacto no gap. Os números de itens testados foram 5, 10 e 15. Realizando um teste estatístico, verifica-se que o gap médio diminui significativamente quando o número de itens aumenta. Entretanto, realizando o mesmo tipo de teste estatístico, a diferença do tempo gasto não é expressivo com o impacto do número de itens. $\mathrm{O}$ número de períodos e de plantas não influenciam no gap médio nem no tempo computacional. Esta heurística foi desenvolvida para resolver um problema integrado de múltiplas plantas que foi observado em uma grande siderúrgica nos Estados Unidos. Em termos de experiência computacional, os autores concluíram que, de forma geral, a heurística de aproximação Lagrangiana obtém boas soluções para este problema. Tal heurística é comparada à proposta nesta dissertação, e os resultados são apresentados na Seção 6.1.1.

\subsection{Complexidade}

Florian et al. (1980) provaram que várias famílias de problemas com um único item e 
custos de preparação são NP-difíceis. Bitran e Yanasse (1982) mostraram que vários problemas de um único item que podem ser resolvidos em tempo polinomial, tornam-se NP-difíceis quando um segundo item é introduzido. Para o CLSP, quando considera-se o tempo de preparação da máquina, o problema de encontrar a solução ótima se torna NP-completo (Maes et al. (1991)).

Em Sambasivan e Schimidt (2002) os autores reduziram o PDL com múltiplas plantas não capacitado ao problema não capacitado de localização facilidades que, por Cornuejols et al. (1977), é NP-difícil. 


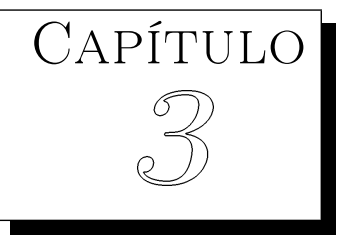

\section{Estudo do problema}

\subsection{CLSP com múltiplas plantas}

Nesta dissertação considera-se o estudo de um ambiente de produção com múltiplas plantas (ou fábricas), em que cada fábrica tem uma demanda própria e o cliente paga, além dos custos dos produtos desejados, o transporte a partir dessa planta. Entretanto, a companhia pagará o custo de transporte entre as plantas, caso a demanda seja atendida por uma fábrica diferente da que foi executado o pedido. O objetivo deste problema é estabelecer a quantidade a ser produzida (ou o tamanho do lote) de cada item em cada uma das plantas em cada um dos períodos de um horizonte de planejamento finito, ou seja, determinar um plano de produção ótimo que deve minimizar os custos de preparação, de produção, de estoque e de transporte entre as plantas, respeitando-se os recursos disponíveis e atendendo a demanda previamente determinada em cada uma das plantas.

Em Sambasivan e Schimidt (2002), o modelo matemático para este problema é descrito a seguir.

\section{Função objetivo}

$$
\min \sum_{i \in N I} \sum_{j \in M I} \sum_{t \in T I}\left[c_{i j t} x_{i j t}+s_{i j t} y_{i j t}+h_{i j} I_{i j t}+\left(\sum_{k \in M I, k \neq j} r_{j k} w_{i j k t}\right)\right]
$$

sujeito a: 


$$
\begin{array}{r}
I_{i j t-1}+x_{i j t}-\sum_{k \in M I, k \neq j} w_{i j k t}+\sum_{l \in M I, l \neq j} w_{i l j t}-I_{i j t}=d_{i j t} \quad i \in N I, j \in M I, t \in T I \\
x_{i j t} \leq\left(\sum_{l=t}^{T} d_{i j l}\right) y_{i j t} \quad i \in N I, j \in M I, t \in T I \\
\sum_{i \in N I}\left(b_{i j t} x_{i j t}+f_{i j} y_{i j t}\right) \leq C_{j} \quad j \in M I, t \in T I \\
I_{i j 0}=0 \quad i \in N I, j \in M I \\
x_{i j t}, I_{i j t} \geq 0 \quad i \in N I, j \in M I, t \in T I \\
w_{i j k t} \geq 0 \quad i \in N I, j, k \in M I, t \in T I \\
y_{i j t} \in\{0,1\} \quad i \in N I, j \in M I, t \in T I
\end{array}
$$

em que:

\section{Parâmetros}

$T$ : é o número de períodos do horizonte de planejamento;

$N$ : é o número de itens;

$M$ : é o número de plantas;

$T I$ : é o conjunto composto pelos elementos $1, \ldots, T$;

$N I$ : é o conjunto composto pelos elementos $1, \ldots, N$;

$M I$ : é o conjunto composto pelos elementos $1, \ldots, M$;

$d_{i j t}$ : é a demanda do produto $i$ na planta $j$ no período $t$;

$C_{j}$ : é a capacidade (tempo) total disponível de produção na planta $j$;

$b_{i j t}$ : é o tempo de produção do item $i$ na planta $j$ no período $t$;

$f_{i j}$ : é o tempo de preparação para produção do item $i$ na planta $j$;

$c_{i j t}$ : é o custo de produção do item $i$ na planta $j$ no período $t$;

$s_{i j t}$ : é o custo de preparação do item $i$ na planta $j$ no período $t$;

$h_{i j}$ : é o custo de estocagem do item $i$ na planta $j$;

$r_{j k}$ : é o custo mínimo de transferência de uma unidade de algum item da planta $j$ para a planta $k$.

\section{Variáveis de decisão}


$x_{i j t}$ : é a quantidade do item $i$ produzida na planta $j$ durante o período $t$;

$I_{i j t}$ : é a quantidade do item $i$ estocada na planta $j$ no final do período $t$;

$w_{i j k t}$ : é a quantidade do item $i$ transferida da planta $j$ para a planta $k$ durante o período $t$

$y_{i j t}$ : é a variável binária que assume o valor 1, caso haja preparação para a produção do item $i$ na planta $j$ no período $t$, e 0 , caso contrário;

O custo mínimo de transferência, $r_{j k}$, representa o menor custo de transferir um dado item da planta $j$ para a $k$. Além disso, o custo de transferência é considerado euclidiano, ou seja, $r_{j l}+r_{l k} \geq r_{j k}$.

A função objetivo fornece o valor da solução do modelo, ou seja, o custo total dedicado ao cumprimento da meta da empresa no planejamento tático de produção. Este custo nada mais é do que a soma dos custos de produção, de preparação, de estocagem e de transferências entre as plantas.

As restrições (3.1) são referentes ao balanceamento de estoque do item $i$ no período $t$ na planta $j$. Elas garantem que a demanda referente ao item $i$ no período $t$ na planta $j$ seja atendida pela produção deste item durante o período $t$ na planta $j$, adicionado da quantidade que foi estocada do item no período anterior na mesma planta, e da quantidade que é transferida das outras plantas para a planta $j$, subtraídos da quantidade do item no período $t$ que é transferida para outras plantas e da quantidade estocada do item $i$ que permanecerá no período $t$ na planta $j$.

As restrições (3.2) garantem que quando houver produção do item $i$ na planta $j$ no período $t$, ou seja, se $x_{i j t}$ for positivo, a variável binária $y_{i j t}$ receba o valor 1 , ou seja, a preparação da planta é considerada. As próximas restrições, (3.3), impedem que a solução do modelo ultrapasse o limite de capacidade disponível, enquanto as restrições (3.4) impõem, sem perda de generalidade, estoques iniciais nulos. Por fim, as restrições (3.5) e (3.6) garantem a não-negatividade das variáveis $x, I$ e $w$, enquanto as restrições (3.7) garantem que $y$ sejam binárias.

Um caso particular do CLSP com múltiplas plantas é o CLSP com máquinas paralelas. Tal problema é composto por múltiplos itens e períodos em um único estágio de produção com máquinas paralelas e envolve a determinação do quanto produzir de um ou mais itens em cada máquina em cada um dos períodos de um horizonte de planejamento finito, de forma a atender à demanda preestabelecida. Tais máquinas apresentam capacidade de produção restrita, e podem produzir os mesmos itens. Como conseqüência, a demanda pode ser atendida por uma ou mais máquinas. O plano de produção resultante deve minimizar a soma dos custos de produção. Pode-se observar que, se considerar no 
CLSP com múltiplas plantas a existência de um único armazém de estoque e custos de transferências nulos, tem-se o CLSP com máquinas paralelas.

\subsection{Estudo do problema não capacitado}

O estudo do PDL com múltiplas plantas não capacitado é importante, pois permite conhecer algumas de suas propriedades, a fim de facilitar o desenvolvimento de um algoritmo eficiente para o CLSP com múltiplas plantas, ou mesmo justificar o uso de outros algoritmos. Algumas propriedades deste problema são apresentadas a seguir, segundo Sambasivan e Schimidt (1999).

Propriedade 3.1 Existe uma solução ótima tal que se $I_{j, t-1}>0$, então $x_{j t}=0, w_{l j t}=0$, para $l \neq j$.

Propriedade 3.2 Existe uma solução ótima tal que se $x_{j t}>0$, então $I_{j, t-1}=0, w_{l j t}=0$, para $l \neq j$.

Propriedade 3.3 Existe uma solução ótima tal que se $w_{l j t}>0$, então $x_{j t}=0, I_{j, t-1}=0$, para $l \neq j$.

Estas três propriedades 3.1, 3.2 e 3.3 indicam que no período $t$, ou é produzida toda a demanda, ou a demanda é atendida por transferência, ou ela é atendida utilizando o estoque do período anterior. Além disso, se houver transferência de uma planta $j$ durante um período $t$, esta transferência será apenas desta planta, como formaliza o Teorema 3.1.

Teorema 3.1 Existe uma solução ótima tal que quando existir transferência de uma planta $j$ durante algum periodo $t$, esta transferência ocorre de uma planta e somente uma.

Se o problema de $m$-plantas for decomposto em $m$ subproblemas de uma única planta, tem-se o seguinte resultado.

Teorema 3.2 Seja $f\left(S P_{j}\right)$ o valor da função objetivo ótima do problema de único item na j-ésima planta e $f(M P)$ o valor da função objetivo da solução ótima do problema de múltiplas plantas com $M$ plantas. Então $\sum_{j=1}^{M} f\left(S P_{j}\right) \geq f(M P)$.

Estas propriedades do problema não capacitado são importantes, pois revelam alguns dos comportamentos de sua solução. O modelo matemático para este problema é o mesmo apresentado na Seção 3.1, exceto pelas restrições de capacidade, restrições (3.3). 


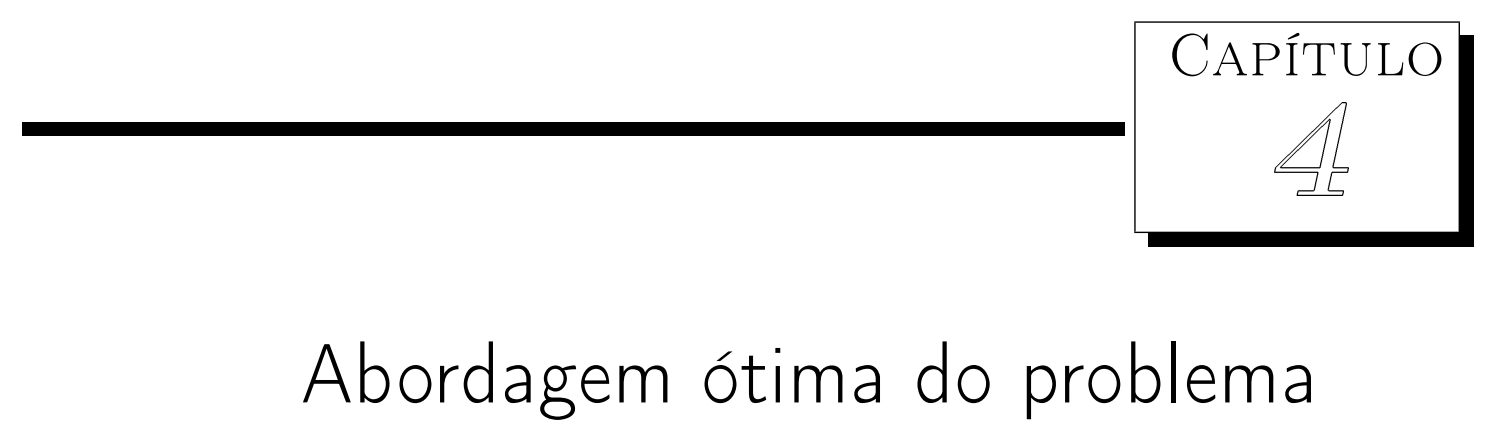

Nas últimas décadas, muitas ferramentas computacionais estão sendo desenvolvidas para resolver problemas de programação inteira. Desde que foi criado, o pacote CPLEX tem avançado muito de uma versão para outra. Um exemplo que demonstra a evolução do pacote é a solução de um modelo de planejamento de produção, cujo objetivo é minimizar o estoque no final de cada dia de um horizonte de planejamento finito. O modelo envolve a produção em uma única facilidade, o transporte é realizado por uma frota dedicada à facilidade e a demanda de armazéns por atacado é assumida determinística. As restrições complicantes são devido à produção diária consecutiva, e ao número mínimo de frotas exigidas. Quando o modelo foi desenvolvido há alguns anos, instâncias reais não podiam ser resolvidas em tempo computacional razoável usando CPLEX 5.0. Com o CPLEX 8.0, este problema de programação inteira pôde ser resolvido em menos de duas horas, obtendo uma solução de boa qualidade (apud Bixby et al. (2002)).

Apesar da evolução, estes pacotes ainda não conseguem encontrar a solução de algumas classes de problemas em tempo razoável. No exemplo anterior, o pacote encontrou uma solução de boa qualidade para uma única instância do problema em aproximadamente duas horas. Note ainda que a solução encontrada não foi a solução ótima. Desta forma, é de grande valia estudar outros algoritmos para que se consiga encontrar soluções de boa qualidade em tempo computacional razoável. Com o intuito de verificar a dificuldade da solução do CLSP com múltiplas plantas de forma exata, um estudo utilizando o pacote de otimização CPLEX 7.5 foi realizado. O objetivo é, com os testes, avaliar o tempo necessário para se obter uma solução ótima, ou próxima da ótima, para instâncias 
pequenas e médias do CLSP com múltiplas plantas.

Para encontrar uma solução, o pacote CPLEX usa a estratégia Branch-and-bound, disponibilizando diferentes opções para a seleção de nós, para a seleção de variáveis, além da disponibilidade de planos de corte, das funções de pré-processamento, entre outras opções. A seguir, as características, o funcionamento e os métodos de solução deste pacote serão brevemente apresentados.

\subsection{Método Branch-and-bound}

O método branch-and-bound ( $B \& B$ ) é muito utilizado para resolver problemas de programação linear inteira e programação linear inteira mista. Muitos pacotes comerciais de programação inteira, assim como o CPLEX, empregam a relaxação linear no algoritmo $B \& B$. Para aplicar estes pacotes de maneira eficiente, é indispensável o entendimento e o uso dos limitantes inferior e superior do valor da função objetivo. Nesta dissertação, este algoritmo será brevemente discutido.

O método $B \& B$ baseia-se em dois princípios básicos: partição e relaxação. A partição consiste em dividir o conjunto de soluções factíveis $S$ do problema original em uma família de conjuntos disjuntos $\left\{S^{i}: i=1, \ldots, k\right\}$. A cada um destes conjuntos é associado um problema de otimização $P^{i}$, formando-se assim, uma lista de problemas. Seja $z_{i}^{\text {sup }}$ e $z_{i}^{\text {inf }}$, respectivamente, os limitantes superior e inferior do subproblema $P^{i}$ e, $z^{\text {sup }}$ e $z^{\text {inf }}$, respectivamente, os limitantes superior e inferior do problema original. O objetivo do método é, em cada subproblema $P^{i}$, determinar um $z_{i}^{\text {inf }}$ e um $z_{i}^{\text {sup }}$ de modo que, no final da execução, tenha-se $z^{i n f}=z^{\text {sup }}$, ou seja, que a solução ótima do problema original seja encontrada. O que motiva as partições do problema é o fato da busca da solução ótima em conjuntos menores ser mais simples e mais rápida.

A partição geralmente é feita de forma recursiva e pode ser representada através de uma árvore. A Figura 4.1 ilustra a partição completa para o caso em que duas variáveis binárias são consideradas. O problema original é representado pelo nó raiz, enquanto os nós filhos representam os subproblemas $P^{i}$. Note que na Figura 4.1, os nós descendentes de um dado nó representam sua partição na região factível. Por exemplo, os nós $S^{00}$ e $S^{01}$ são descendentes de $S^{0}$.

Os valores de $z^{\text {inf }}$ e $z^{\text {sup }}$ são atribuídos de acordo com o problema a ser estudado. Se for um problema de minimização, o valor inicial para $z^{\text {sup }}$ é, geralmente, o valor da função objetivo de alguma solução factível do problema, enquanto $z^{\text {inf }}$ é obtido pela relaxação linear do problema, ou seja, as variáveis inteiras do problema original são consideradas 


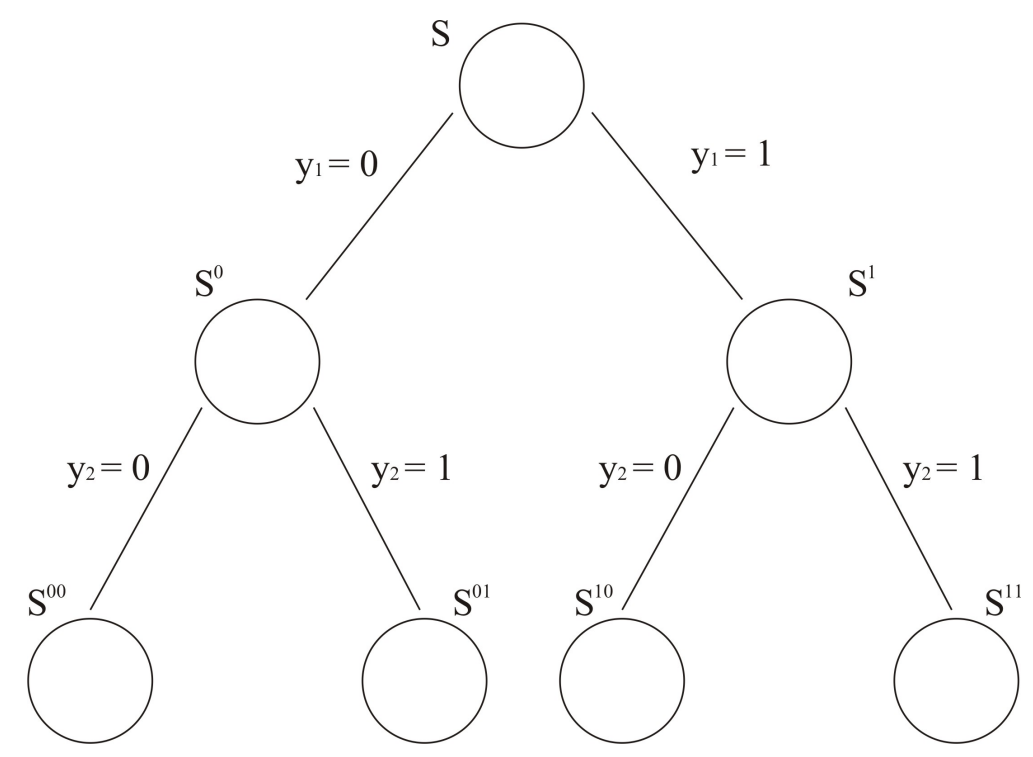

Figura 4.1: Árvore da partição.

reais para o problema relaxado. Logo, o valor da solução do problema relaxado é menor ou igual à solução do problema inteiro. Se a solução do problema relaxado for factível para o problema inteiro, a solução ótima foi obtida. Caso contrário, a execução do método continua através de ramificação das variáveis, como ilustra a Figura 4.1, cuja meta é aumentar o limitante inferior e/ou diminuir o limitante superior.

Considerando-se ainda o problema de minimização, os limitantes inferiores dos subproblemas são obtidos da mesma maneira como os do problema original. A atualização do limitante superior é realizada quando uma solução factível menor do que a atual for obtida. A partição de um conjunto $S^{i}$ é interrompida quando uma das condições a seguir for satisfeita. Essas condições são chamadas de testes de sondagem.

(TS1) $\quad S^{i}=\emptyset ;$

(TS2) uma solução ótima de $P^{i}$ é encontrada, $z_{i}^{\text {inf }}=z_{i}^{\text {sup }}$;

(TS3) o valor de qualquer solução factível de $P^{i}$ é pior ou igual ao valor da melhor solução factível atual (solução incumbente).

Quando uma destas três condições ocorre, o nó correspondente a $S^{i}$ pode ser descartado (sondado), pois todas as suas soluções factíveis estão implicitamente enumeradas.

É evidente que quanto melhor for a qualidade do limitante inferior, mais fácil é sondar um nó e, portanto, a árvore $B \& B$ terá menos nós. O ideal é ter um problema relaxado de fácil resolução que forneça limitantes inferiores de boa qualidade. Infelizmente, em geral, estes dois atributos são antagônicos, isto é, um problema relaxado de muito fácil resolução produz, quase sempre, um limitante inferior pobre. No caso do CPLEX, que usa relaxação linear, tem-se um dos limitantes inferiores de mais simples solução que fornece, 
entretanto, um limitante nem sempre muito bom.

Além da qualidade do limitante, existem outros dois fatores que afetam a eficiência do método $B \& B$ tais como: a escolha do próximo subproblema da lista, ou seja, em que ordem resolver os subproblemas da árvore; e a escolha da variável de ramificação que separa o conjunto $S^{i}$ em dois conjuntos, ou seja, que critérios usar para escolher as variáveis de ramificação.

As regras utilizadas para a escolha do nó e da variável dependem do estudo do problema. Atamtürk e Savelsbergh (2004) analisam as regras utilizadas no pacote CPLEX. Neste trabalho, o desempenho das regras de escolha de nó e de escolha de variáveis de ramificação disponíveis no CPLEX 7.5 é avaliado, como é descrito a seguir.

\subsection{Primeira etapa de testes}

Para realizar a primeira etapa de testes com o pacote CPLEX, as instâncias F1 à F30 propostas em Trigeiro et al. (1989) para o CLSP foram adaptadas inserindo-se outras plantas e custos de transferências entre elas. A partir destas instâncias, dois grupos foram elaborados. No primeiro grupo, Grupo 1, foram utilizadas as instâncias originais do autor considerando apenas os seis primeiros períodos e os três primeiros itens, e duas plantas análogas à primeira planta foram acrescentadas na instância, com custos de transferências unitários entre as três plantas. Já o segundo grupo de instâncias, Grupo 2, é análogo ao primeiro conjunto, com diferença nos custos de produção: para a primeira planta foram mantidos os custos de produção originais; para a segunda planta os custos são $10 \%$ mais caros; e para a última planta, os custos são 10\% mais baratos. Na realização dos testes, foi estabelecido um tempo limite de 600 segundos para a execução de cada instância. Como será visto na tabela de resultados, alguns exemplos foram resolvidos dentro deste tempo limite, entretanto, muitos não chegaram ao gap estabelecido (0.01\%), sabendo que:

$$
g a p=\frac{(\text { limitante superior-limitante inferior })}{\text { limitante inferior }} * 100 \%
$$

em que estes limitante inferior e limitante superior são os limitantes obtidos pelo branchand-bound no CPLEX.

Estes testes foram divididos em duas etapas, sendo todos os testes realizados no pacote CPLEX 7.5. A primeira etapa consiste de dois experimentos: no primeiro experimento, os dois grupos de instâncias foram executados variando-se a estratégia de seleção de nós; enquanto no segundo experimento, os grupos de instâncias foram executados variando-se a estratégia de escolha de variáveis. As Tabelas 4.1, 4.2, 4.3 e 4.4, a seguir, 
apresentam os resultados obtidos pelas diversas estratégias. A primeira e a segunda colunas indicam, respectivamente, o gap e o tempo médios das 30 instâncias executadas, enquanto a última coluna, representada por NIR, indica o número de instâncias resolvidas dentro do tempo e do gap estabelecidos.

\subsubsection{Experimento 1}

A primeira variação de estratégia do pacote a ser considerada é o método de seleção de nós. Este método consiste no critério de escolha dos nós da árvore $B \& B$ que serão ramificados. As opções disponíveis no pacote, denominadas estratégias, são:

0 - Busca em profundidade: Nessa estratégia de busca, um dos nós do nível mais profundo da árvore de busca sempre é expandido;

1 - Busca pelo melhor limitante: O nó com a melhor função objetivo será selecionado;

2 - Busca pela melhor estimativa: O progresso da factibilidade inteira do nó relativo à degradação do valor da função objetivo será estimado;

3 - Busca alternativa da melhor estimativa: Uma variante da anterior.

Tabela 4.1: Soluções do Grupo 1 no Experimento 1.

\begin{tabular}{cccc}
\hline Estratégia & Gap médio (\%) & Tempo médio (s) & NIR \\
\hline $\mathbf{0}$ & 1.66 & 313.60 & 16 \\
$\mathbf{1}$ & 0.29 & 292.72 & 19 \\
$\mathbf{2}$ & 0.38 & 282.88 & 20 \\
$\mathbf{3}$ & 0.85 & 295.06 & 19 \\
\hline
\end{tabular}

Na Tabela 4.1 são apresentados os resultados para o primeiro conjunto de instâncias, Grupo 1, isto é, as instâncias com custos de produções iguais entre as plantas. Observe que a Estratégia 1 foi a que obteve o melhor gap médio, no entanto, resolveu 19 instâncias, enquanto a Estratégia 2 resolveu 20 instâncias com gap bastante próximo ao anterior. Em 16 das 30 instâncias, todas as estratégias conseguiram resolver os problemas respeitando o tempo e o gap estabelecidos. O maior gap obtido foi de $10.45 \%$ para a instância F20, usando a Estratégia 0. Foi observado que as Estratégia 1 e 3 resolveram as mesmas instâncias; que todas estratégias resolveram as 16 instâncias que a Estratégia 0 resolveu; e que a Estratégia 3 resolveu, além das instâncias que as outras estratégias resolveram, 1 instância a mais. A Estratégia 0 foi a que apresentou o pior desempenho neste conjunto de instâncias, com maiores gap e tempo médios, e menor número de soluções encontradas dentro do tempo limite. 
Tabela 4.2: Soluções do Grupo 2 no Experimento 1.

\begin{tabular}{cccc}
\hline Estratégia & Gap médio (\%) & Tempo médio (s) & NIR \\
\hline $\mathbf{0}$ & 2.57 & 488.08 & 9 \\
$\mathbf{1}$ & 0.51 & 434.06 & 12 \\
$\mathbf{2}$ & 0.55 & 447.92 & 12 \\
$\mathbf{3}$ & 1.62 & 441.88 & 11 \\
\hline
\end{tabular}

Nas instâncias com custos de produção diferenciados, Grupo 2, a Estratégia 1 obteve os melhores resultados, como pode ser observado na Tabela 4.2, com os menores gap e tempo médios e, juntamente com a Estratégia 2, obteve o maior número de soluções factíveis para os 600 segundos de execução. Novamente, a Estratégia 0 foi a que se comportou de maneira mais ineficiente, com os piores resultados, tanto de gap e tempo médios, como de número de instâncias resolvidas. Além disso, esta estratégia obteve o maior gap dentre todas instâncias testadas, com um valor $10.95 \%$ relativo à instância F9.

A partir dos resultados acima, pode-se concluir que o método de seleção de nós que se comportou melhor para estas duas classes de instâncias foi a Estratégia 1, que é a estratégia padrão do CPLEX.

\subsubsection{Experimento 2}

Neste experimento, as instâncias foram resolvidas variando-se os métodos de seleção de variáveis de ramificação. O método de seleção de variáveis consiste em determinar qual variável inteira com valor real no nó escolhido será ramificada. As opções disponíveis no pacote são:

-1 - Infactibilidade do menor inteiro: Ramifica a variável fracionária cuja fração está mais próxima de um inteiro;

0 - Automática: O pacote determina a estratégia;

1 - Infactibilidade do maior inteiro : Ramifica a variável fracionária cuja fração está mais próxima de 0.5 ;

2 - Pseudocustos: Deduz uma estimativa sobre o efeito de cada ramificação proposto através de informação de dualidade;

3 - Divisão forte: Analisa potenciais ramificações por melhoramento de um pequeno número de iterações simplex;

4 - Pseudocustos reduzidos: Uma versão computacionalmente mais barata de pseudocustos. 
Também é possível implementar uma estratégia específica para as ramificações das variáveis, entretanto, foram utilizadas apenas as opções disponíveis no pacote. Neste caso, a Estratégia 0 é a estratégia padrão do pacote.

Tabela 4.3: Soluções do Grupo 1 no Experimento 2.

\begin{tabular}{cccc}
\hline Estratégia & Gap médio (\%) & Tempo médio (s) & NIR \\
\hline $\mathbf{- 1}$ & 2.00 & 560.07 & 2 \\
$\mathbf{0}$ & 0.29 & 310.46 & 19 \\
$\mathbf{1}$ & 0.29 & 292.10 & 19 \\
$\mathbf{2}$ & 0.29 & 292.09 & 19 \\
$\mathbf{3}$ & 0.50 & 402.66 & 13 \\
$\mathbf{4}$ & 0.54 & 485.96 & 9 \\
\hline
\end{tabular}

Pode-se observar pela Tabela 4.3 que, apesar dos gaps médios e os NIR's terem empatado entre as Estratégias 0, 1 e 2 considerando o Grupo 1, estas estratégias apresentaram diferenças no valor do tempo médio, sendo a Estratégia 2 a que obteve o menor valor desta variável. A Estratégia padrão foi a terceira melhor, com um tempo médio superior às Estratégias 1 e 2. As Estratégias 0, 1 e 2 resolveram as mesmas instâncias no tempo delimitado, sendo a Estratégia -1, a que obteve o menor número de soluções resolvidas, além desta estratégia apresentar os piores gaps e tempo médios. As Estratégias 3 e 4, além de apresentarem um número inferior à metade do número de instâncias resolvidas pelas Estratégias 0, 1 e 2, também obtiveram gap e tempo médios significativamente superiores a estas estratégias.

Tabela 4.4: Soluções do Grupo 2 no Experimento 2.

\begin{tabular}{cccc}
\hline Estratégia & Gap médio (\%) & Tempo médio (s) & NIR \\
\hline $\mathbf{- 1}$ & 2.72 & 580.05 & 1 \\
$\mathbf{0}$ & 0.51 & 433.62 & 13 \\
$\mathbf{1}$ & 2.72 & 565.95 & 3 \\
$\mathbf{2}$ & 0.51 & 433.67 & 13 \\
$\mathbf{3}$ & 0.68 & 502.98 & 8 \\
$\mathbf{4}$ & 0.51 & 433.46 & 12 \\
\hline
\end{tabular}

Observando a Tabela 4.4, verifica-se que as Estratégias 0 e 2 novamente empataram com respeito ao valor dos gaps médios e ao número de soluções resolvidas, resultados estes relativos ao Grupo 2. Entretanto, desta vez, a estratégia que obteve o melhor tempo médio foi a Estratégia 0. Por outro lado, a diferença de tempo entre as estratégias é bem baixa, sendo de 0.05 segundos, ao contrário do comportamento do outro conjunto de problemas, em que a diferença era de mais de dezoito segundos. 
Desta forma, de uma maneira geral, pode-se concluir que a Estratégia 2 foi a mais eficiente para este conjunto de problemas. No entanto, a estratégia padrão CPLEX tem um desempenho muito competitivo.

Em resumo, observando os dois experimentos realizados, é possível concluir que a configuração padrão do CPLEX é competitiva e pode ser adotada para a solução do problema estudado na Seção 4.3.

\subsection{Segunda etapa de testes}

Nesta etapa, foram realizados testes no CPLEX 7.5 usando 40 instâncias que são utilizadas na Seção 6.1.2 para avaliar o desempenho da heurística proposta. Tais instâncias contém 6 períodos, 15 itens e 4 plantas e foram geradas de acordo com Toledo e Armentano (2006) para máquinas paralelas, incluindo custos de transferências entre as plantas da mesma maneira que foram gerados os custos de estoque para cada planta. Para tais instâncias, o tempo limite foi de 1800 segundos e o gap mínimo foi de $0.01 \%$, sendo que cada classe representa 5 instâncias. Na Tabela 4.5 são reportados os valores médios e o número de instâncias resolvidas de cada classe, NIR.

Para identificar cada classe de instâncias, foi utilizada uma nomenclatura de acordo com os parâmetros: capacidade, normal ou apertada, respectivamente, $\mathrm{N}$ ou A; custo de preparação, alto ou baixo, respectivamente, A ou B; e tempo de preparação, alto ou baixo, respectivamente, A ou B. Considere cada classe identificada por tipo capacidade/tipo de custo de preparação/tipo de tempo de preparação. Então, por exemplo, a classe de instâncias com capacidade normal, baixo custo de preparação e alto tempo de preparação é denotado por NBA.

Tabela 4.5: Testes realizados para outras instâncias.

\begin{tabular}{|c|c|c|c|}
\hline Classe & Gap médio (\%) & Tempo médio (s) & NIR \\
\hline AAA & 9.2 & 1800.2 & 0 \\
\hline NAB & 8.8 & 1800.2 & 0 \\
\hline $\mathrm{AAB}$ & 9.5 & 1800.2 & 0 \\
\hline NAA & 8.4 & 1800.3 & 0 \\
\hline NBB & 0.06 & 757.0 & 4 \\
\hline ABA & 0.1 & 1182.6 & 3 \\
\hline $\mathrm{ABB}$ & 0.1 & 1106.1 & 3 \\
\hline NBA & 0.05 & 629.6 & 4 \\
\hline Médias & 4.6 & 1359.6 & 1.7 \\
\hline
\end{tabular}

Pela Tabela 4.5, pode-se observar que não foi encontrado um gap menor ou igual 
a $0.01 \%$ dentro dos 1800 segundos fixados para nenhuma das 5 instâncias das classes de alto custo de preparação. Com relação às outras classes de instâncias, pelo menos uma instância o CPLEX não encontrou solução com gap menor ou igual $0.01 \%$ dentro do tempo estabelecido. 



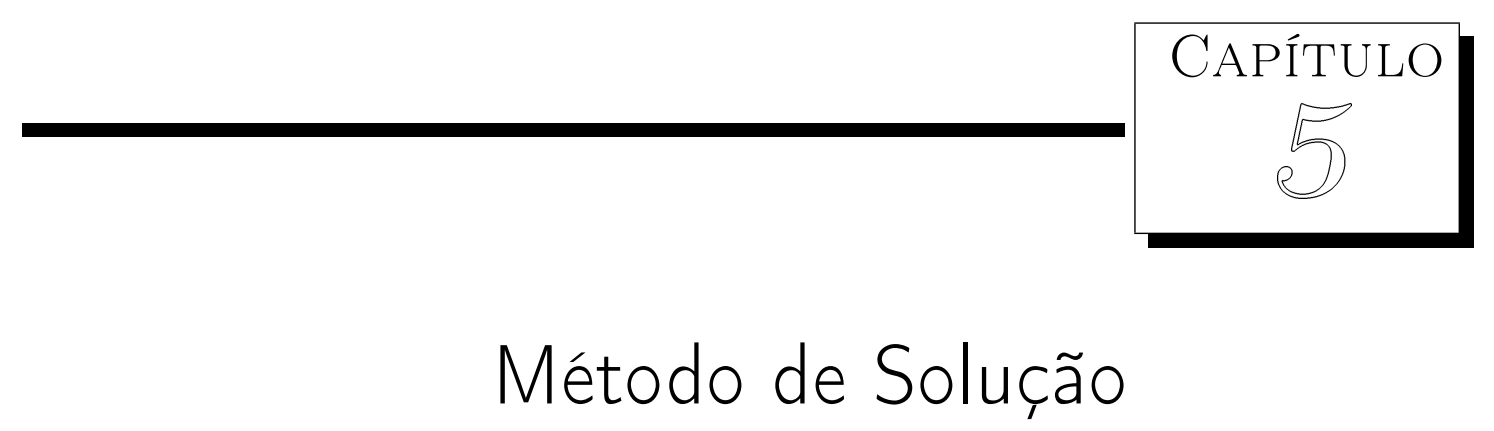

O problema estudado pertence à área de otimização combinatória e é, na maioria das vezes, intratável em situações reais. Por esta razão é proposta, nesta dissertação, uma heurística para a solução do problema. As heurísticas são algoritmos que buscam encontrar uma solução próxima da ótima, em um tempo computacional razoável.

Segundo Maes et al. (1991), as heurísticas podem ser classificadas em dois grupos: o primeiro baseado na teoria de otimização e programação matemática e o segundo, na intuição de especialistas sobre o problema estudado. O primeiro grupo tem a vantagem de ser fácil de se obter limitantes, os quais são totalmente confiáveis. Já o segundo grupo tem como vantagens as observações práticas e, segundo Diaby et al. (1992a) são, em geral, mais rápidas computacionalmente e mais transparentes. Um grupo particular das heurísticas é composto pelas meta-heurísticas. Elas podem ser definidas como uma estrutura de algoritmo de alto nível que podem ser especializadas para resolver problemas de otimização. Além disso, é uma estratégia que guia outras heurísticas na busca por soluções factíveis. Nesta dissertação, a meta-heurística GRASP (Greedy Randomized Adaptive Search Procedures) e path relinking foram usadas na construção da heurística proposta. 


\subsection{Meta-heurística GRASP}

O GRASP é uma estratégia composta por múltiplos inícios e foi inicialmente proposto por Feo e Resende (1989) e mais formalmente em Pitsoulis e Resende (1995). Cada iteração de GRASP consiste em duas fases: construção de uma solução inicial e busca local.

Na primeira fase, a construtiva, é criada uma lista restrita de candidatos (LRC) que é formada pelos elementos cuja incorporação à solução parcial leva aos menores custos incrementais. Estes elementos podem ser, por exemplo, lotes de produção, lotes de estoque, ou seja, valores para as variáveis de decisão. A introdução de elementos pára quando a solução tornar-se factível, ou seja, quando a solução atender todas as restrições do problema. A LRC é criada de acordo com as seguintes definições:

- Defina $g(s)$ como sendo o custo incremental ao se incorporar o elemento $s$ à solução parcial;

- Defina gmin e gmax como, respectivamente, os custos incrementais mínimo e máximo;

- Seja a LRC formada por todo elemento $s$ que não torna a solução parcial infactível, sendo $s$ pertencente ao conjunto de todos os elementos tal que $g(s) \in[$ gmin, gmin + $\alpha(\max -\operatorname{gmin})], \operatorname{com} \alpha \in[0,1]$.

Pode-se observar que a meta-heurística apresentada nesta seção é baseada em um processo inicial semiguloso, pois a incorporação de elementos da LRC na solução não leva somente em consideração o elemento que gera o melhor custo incremental. Ela estabelece uma faixa de elementos, os melhores elementos, ou seja, os que tenham os menores custos incrementais, e então escolhe aleatoriamente um deles. Isto permite gerar diferentes soluções iniciais, as quais passam pela fase de busca local para melhoria da solução.

A Fase Construtiva da meta-heurística, denominada Greedy Randomized Construction, é descrita no Algoritmo 2.

Um pseudocódigo do GRASP é apresentado no Algoritmo 3. Considere MaxIterações e INFINITO, respectivamente, o número máximo de iterações do GRASP, e um valor superior a qualquer solução factível do problema. Seja Semente os dados necessários para a construção da solução, e a função Leia Entrada() responsável pela leitura de dados do problema. A função Busca-Local(Solução) executa a busca local na Solução procurando na vizinhança de tal solução, uma de menor valor. 

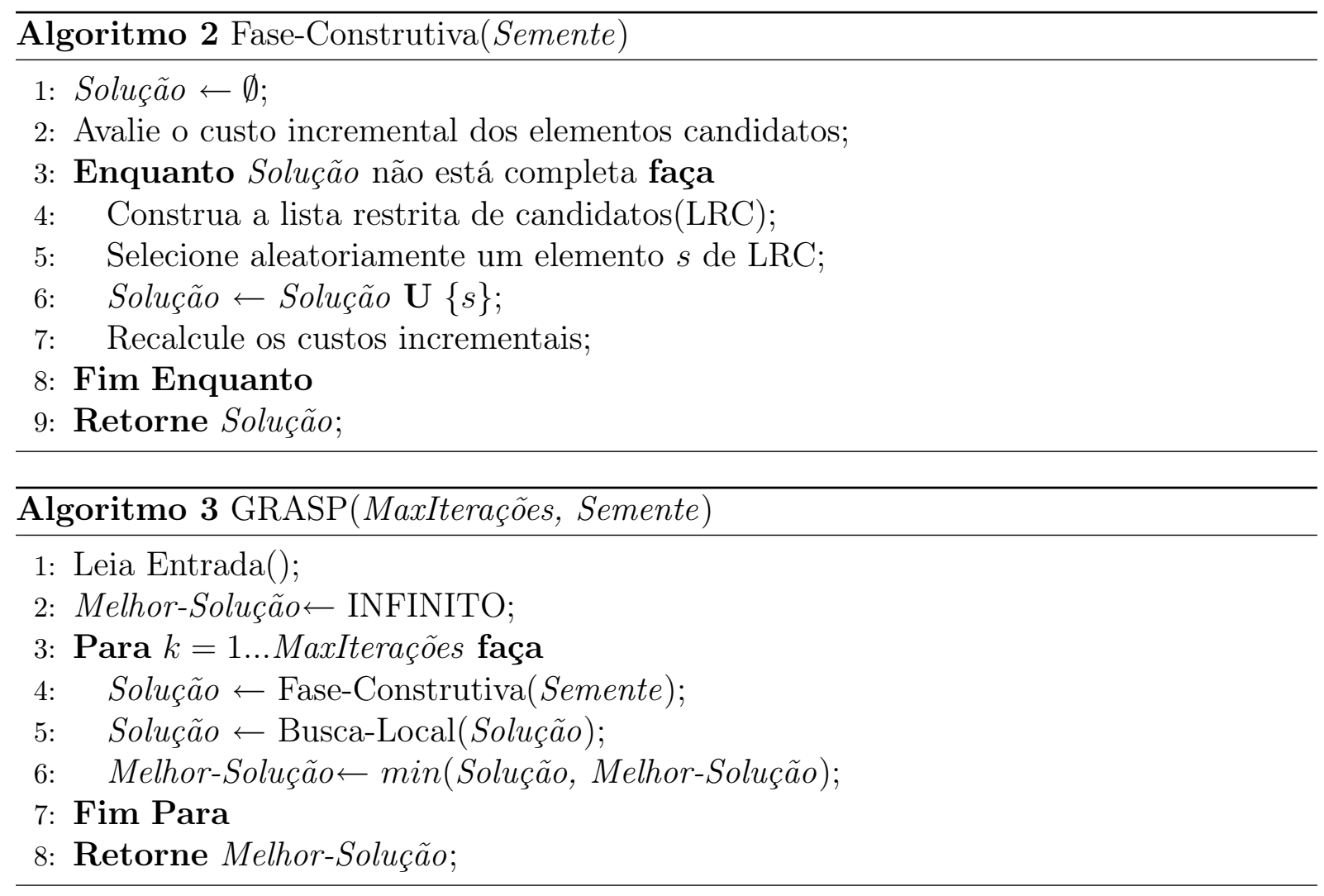

O GRASP é executado por um número máximo de iterações. Este número corresponde à quantidade de soluções factíveis encontradas pela fase construtiva em que foram aplicadas a busca local. Dentre as soluções geradas é escolhida aquela de melhor valor.

Na literatura podem ser encontrados vários problemas em que o GRASP foi aplicado e obteve bons resultados, como o Problema Quadrático de Designação (Li et al. (1994)), o Problema de Planarização de Grafos (Resende e Ribeiro (1997)) e o Problema de Recobrimento Máximo (Resende (1998)).

\subsection{Busca Local}

A busca local é usada com freqüência para resolver problemas de otimização combinatória e serve principalmente como estratégia de apoio a outros algoritmos como o GRASP e a busca tabu. Isto se deve ao seu conceito de estratégia iterativa de melhoria que consiste de, dado um ponto ou uma solução inicial $x$, analisar soluções próximas a $x$ denominada vizinhança de $x, V(x)$, tendo como meta uma solução de melhor valor. Se uma solução melhor for encontrada, então segue a busca pela vizinhança desta solução de melhor valor. A busca vai seguindo até que não haja uma solução de melhor valor, quando é então encontrado o ótimo local. Por exemplo, se a busca local tem como objetivo encontrar o mínimo local, a análise da vizinhança será em busca de uma solução de menor valor em 
relação a $x$. Assim que não for mais encontrada uma solução de menor valor, partindo de uma referida solução inicial $x$, então tal solução será chamada de mínimo local. Outro critério de parada da busca local que pode ser utilizado é um número limitado de iterações. No Algoritmo 4 é ilustrado um algoritmo básico de busca de um mínimo local, avaliado por uma função $f(x)$.

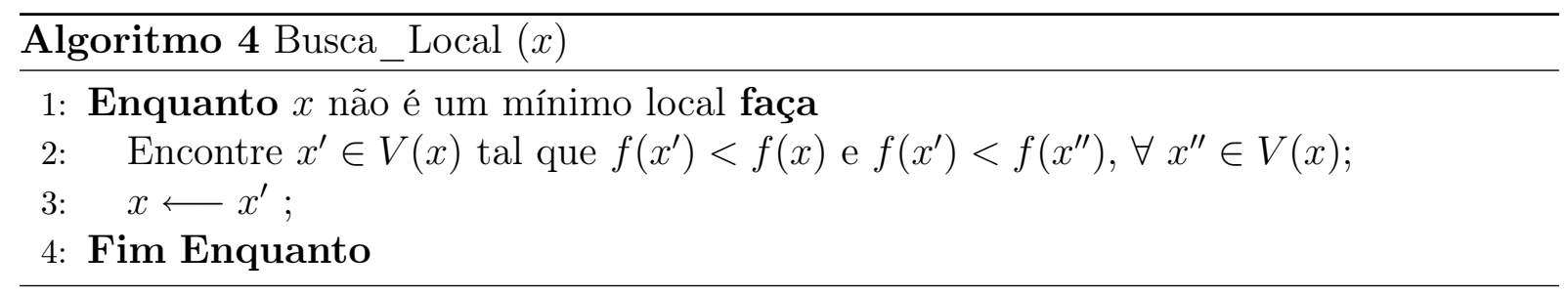

Existe um grande número de variações na busca local. Vale citar dois métodos explorados na implementação do algoritmo de busca local do GRASP que são o método da descida e o método da máxima descida. O método da descida analisa a vizinhança ponto a ponto, ou seja, verifica se uma dada solução da vizinhança é melhor do que a atual e já segue procurando pela vizinhança desta solução de melhor valor mesmo que esta solução não seja a de melhor valor desta vizinhança. Enquanto isso, o método da máxima descida analisa a vizinhança toda buscando diretamente a melhor solução desta vizinhança, como foi descrito no Algoritmo 4.

Os algoritmos de busca local têm algumas deficiências. Alguns exemplos são: o não-conhecimento da distância do ótimo local ao global e a dependência da solução inicial para a obtenção do resultado. Uma estratégia para amenizar o problema da diminuição da distância do ótimo local ao global é a escolha de mais de um ponto de partida para executar a busca local. Assim, é escolhida a melhor solução dentre as encontradas, obtendo-se, em geral, uma solução de melhor qualidade do que se tivesse partido de uma única solução. O GRASP, com sua estratégia de múltiplos inícios, irá gerar vários pontos de partida e executar a busca local a partir de todos. Por fim, a solução que tiver menor valor será escolhida.

\subsection{Meta-heurísticas path relinking e scatter search}

Path relinking (PR) e scatter search (SS) são algoritmos evolutivos que permitem princípios unificadores de soluções baseados na construção de caminhos e no uso de estruturas que combinam as soluções. Estes procedimentos foram inicialmente propostos por Crowston et al. (1963) para o problema de job shop scheduling e são uma vantagem significativa na resolução de uma variedade de problemas complexos de otimização. Algumas das aplicações destes métodos podem ser encontrados em Rochat e Taillard (1995) e Kelly e Xu 
(1996).

Assim como os outros métodos evolutivos, estas meta-heurísticas combinam e exploram as soluções a partir de uma população. Esta população de soluções é denominada conjunto de referência que é relativamente pequeno se comparado à população de outros algoritmos, como por exemplo os algoritmos genéticos ${ }^{1}$.

O SS escolhe duas ou mais soluções do conjunto de referência para criar novas soluções. Esta estratégia combina soluções para capturar informações não contidas nas soluções originais, com a vantagem adicional de ter heurísticas auxiliares para seleção das soluções a serem combinadas. Além disso, o SS não está restrito a uma única forma de combinar soluções, pois podem ser consideradas combinações lineares com diversos pesos, o que possibilita a exploração de estratégias para a escolha da melhor para determinada implementação.

O SS consiste de cinco etapas principais:

1. Um método de diversificação para gerar um conjunto diversificado de soluções.

2. Um método de melhoria para transformar as soluções do conjunto de soluções em uma ou mais soluções melhores que podem participar do conjunto diversificado de soluções. É importante observar que as soluções do conjunto e as encontradas na melhoria precisam ser factíveis.

3. Um conjunto de referência atualizado para construir e manter um conjunto com as $n$ melhores soluções encontradas, com $n \leq 20$ basicamente.

4. Um método para gerar subconjuntos para operar no conjunto de referência, cujas soluções que formam estes subconjuntos servirão de base para combinar as soluções. O método mais comum de formar subconjuntos é gerar todos os pares do conjunto de referência, ou seja, todos subconjuntos de tamanho 2 .

5. Um método de combinar as soluções para transformar um dado subconjunto de soluções, gerados na Etapa 4, em uma ou mais soluções combinadas.

Enquanto isso, a idéia básica do PR é, dado um número finito de soluções de melhor qualidade denominadas soluções de elite, construir caminhos entre duas delas de forma

\footnotetext{
${ }^{1}$ Os algoritmos genéticos são algoritmos evolutivos que simulam a reprodução e a competição de indivíduos de uma espécie (Goldberg (1989)). Nesses algoritmos, o processo de otimização ocorre em várias gerações, cada geração é representada por uma população de soluções ou indivíduos. Um indivíduo é associado a uma possível solução do problema, que é codificada em um vetor. Operadores genéticos são utilizados para gerar novas soluções a partir das soluções atuais. Um desses operadores, o operador de cruzamento (cross-over), troca trechos de duas soluções (pais) para gerar um novo conjunto de soluções (filhos). Outro operador, a mutação, geralmente é utilizado após a aplicação do operador de cruzamento. Ele é um operador secundário que altera as soluções da população atual com uma pequena probabilidade.
} 
que se possa avaliar o valor das soluções intermediárias pertencentes a tal caminho. Tal concepção surgiu naturalmente do SS pois esta estratégia combina soluções, o que possibilita gerar caminhos entre as soluções, além de explorar soluções na vizinhança destas soluções. Os movimentos são realizados através da seleção daqueles que introduzam atributos contidos na solução guia, a solução final, partindo da solução inicial dada (Glover e Laguna (1997)). As soluções encontradas nos caminhos podem ser de melhor valor do que a melhor solução obtida até o momento, como pode ser observado na Figura 5.1, considerando o eixo vertical correspondente ao valor da solução.
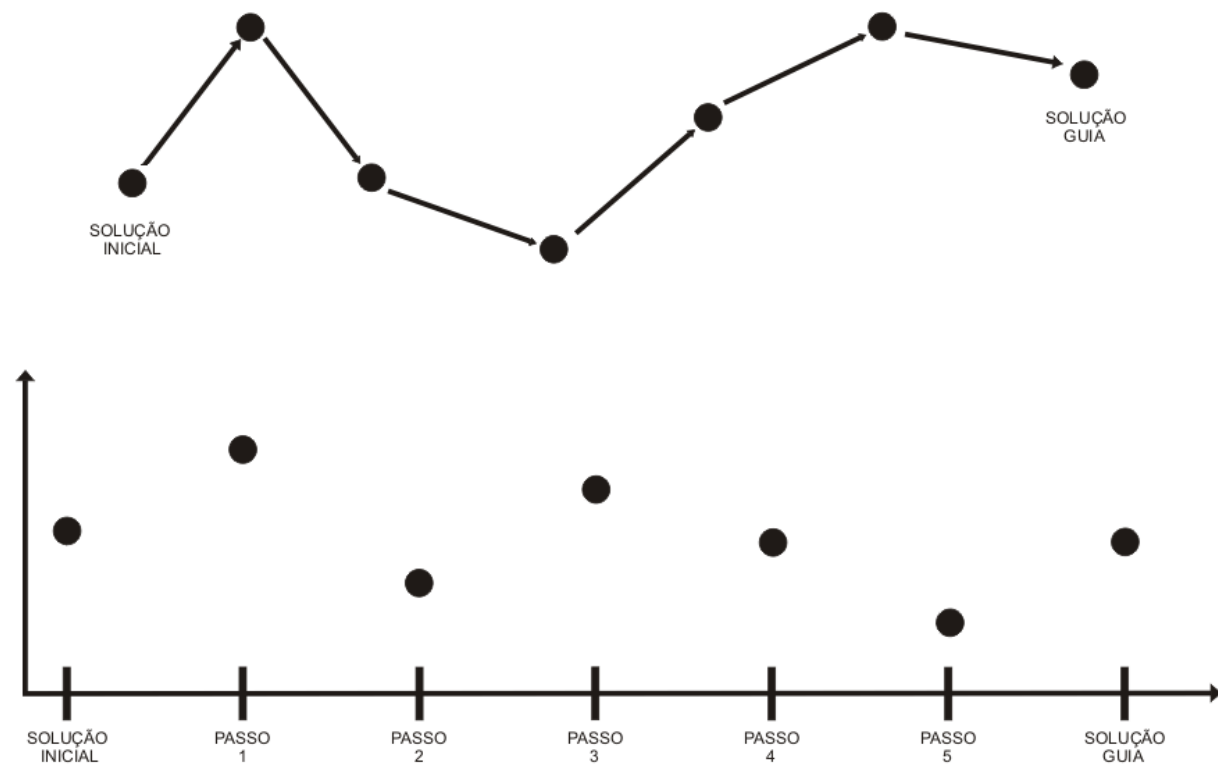

Figura 5.1: Exemplo de path relinking.

Variações da estratégia de PR são encontradas e citadas a seguir:

\section{- Variação e Desbravamento}

Esta primeira variante consiste de, dadas duas soluções iniciais $s^{\prime}$ e $s^{\prime \prime}$ diferentes dentre o conjunto de soluções de elite, criar dois caminhos a partir delas, ou seja, uma seqüência de soluções partindo delas. As soluções finais destes dois caminhos devem ser as mesmas, isto é, deve haver um encontro destes dois caminhos. Esta estratégia tem como objetivo a variação da vizinhança, partindo de duas soluções diferentes. Além disso, tem o fator desbravamento que é explorado pelas vizinhanças diferentes tendo, como conseqüência, a possibilidade de alcançar soluções que são desconsideradas pela estratégia padrão.

\section{- Conexão Extrapolada}


Neste caso, duas soluções de elite $s^{\prime}$ e $s^{\prime \prime}$ são escolhidas e a trajetória entre elas é produzida de forma a mudar as conexões originais. Tal mudança é realizada com a mesma idéia de que as soluções intermediárias a $s^{\prime}$ e $s^{\prime \prime}$ são suas combinações lineares, o que pode levar a combinação a ir além das soluções originais. Os pontos exteriores (que extrapolaram $s^{\prime}$ e $s^{\prime \prime}$ ) criam uma diversificação análoga ao SS, pois possibilitam diferentes combinações das soluções limites.

\section{- Múltiplos Geradores}

Tendo como base de conhecimento o fato de que novos pontos podem produzir diversos "geradores", tal estratégia foi idealizada. Desta forma, ao invés de escolher apenas duas soluções de elite $s^{\prime}$ e $s^{\prime \prime}$ para gerar a trajetória, é escolhida uma coleção de soluções para tal fim. Como conseqüência, esta estratégia de múltiplos "geradores" produz novos elementos por um processo que se assemelha à estratégia original SS, em uma generalização de maior nível que favorece o alcance de zonas promissoras.

\section{- Vizinhanças Construtivas}

Neste caso, as soluções guias consistem de subconjuntos de soluções de elite, como no caso anterior de múltiplos geradores, mas com a diferença da solução inicial começar como solução incompleta ou mesmo vazia em alguns componentes destas soluções, como se os valores das variáveis não fossem atribuídos ainda. O uso da vizinhança construtiva permite que a solução inicial se mova em direção às soluções guias, por uma vizinhança que progressivamente introduza elementos contidos nas soluções guias, ou que sejam avaliadas como atrativas a partir da decomposição destas soluções.

\section{- Construção de Vocabulário}

Esta última estratégia cria estruturas de combinações não apenas usando elementos primitivos de vizinhanças habituais, mas também construindo e unindo partes complexas de tais elementos. Tal denominação é devido à analogia do processo de construção progressiva de frases, sentenças e parágrafos que a cada nível podem ser vistas como palavras de alta ordem. O objetivo de tal estratégia é levar vantagem destes contextos, onde configurações parciais de soluções originam soluções de boa qualidade.

No algoritmo desenvolvido para esta dissertação, a estratégia path relinking foi incorporada ao GRASP para intensificar a busca por soluções de boa qualidade. Apesar de algumas abordagens escolherem o conjunto de soluções de elite, priorizando a diversidade e não necessariamente as soluções de menor custo, serão apresentados os procedimentos 
em que as soluções de elite são as soluções de menor custo resultantes do GRASP. Na literatura não se encontra estudo de GRASP com path relinking para os problemas de dimensionamento de lotes, apesar de ser encontrado em diversos problemas de otimização como Resende e Ribeiro (2003) Laguna e Martí (1999) e Ribeiro et al. (2002).

\subsection{Heurística proposta}

A meta-heurística GRASP com path relinking proposta consiste basicamente de três fases na ordem citada a seguir:

1. Fase construtiva da solução inicial;

2. Busca local da solução inicial;

3. Estratégia de path relinking do algoritmo.

Como se pode observar, as duas primeiras etapas consistem do GRASP, enquanto a última é a fase de melhoria e diversificação da heurística. A seguir, tais etapas são descritas separadamente.

\subsubsection{Solução inicial}

A estratégia adotada para gerar a solução foi considerar o algoritmo polinomial para o problema de máquinas paralelas não capacitado proposto por Sung (1986). Para tanto, os custos de transferências e a existência de mais de um armazém de estoque do problema foram desconsiderados, ou seja, a demanda é produzida em uma certa planta e lá mesmo é estocada, mesmo que o custo de estoque de outra planta seja menor. Logo, a solução do algoritmo de Sung (1986) fornece apenas uma solução factível e não uma solução ótima para o PDL com múltiplas plantas não capacitado.

Para cada item $i$, defina $\Gamma_{i j k t}$ como o custo de produção do item $i$ na planta $j$ no período $k+1$, para atender a demanda do item $i$ dos períodos $k+1$ ao $t$ de todas as plantas, ou seja, $d_{i k t}^{\prime}=\sum_{j=1}^{M} \sum_{r=k+1}^{t} d_{i j r}$, com $k<t$ e $t=1 \ldots T$. Logo,

$$
\Gamma_{i j k t}= \begin{cases}s_{i j}+c_{i j, k+1} d_{i k t}^{\prime}+\sum_{r=k+2}^{t-1} h_{i j} d_{i r t}^{\prime} & \text { se } d_{i k t}^{\prime}>0 \\ 0 & \text { se } d_{i k t}^{\prime}=0\end{cases}
$$

em que 
$s_{i j}$ : custo de preparação do item $i$ na planta $j$;

$c_{i j t}$ : custo de produção do item $i$ na planta $j$ no período $t$;

$h_{i j}$ : custo de estoque do item $i$ na planta $j$;

$M$ : é o número de plantas;

T: é o número de períodos no horizonte de planejamento.

Seja $\zeta_{i t}$ o custo de produção mínimo do período 1 ao $t$ do item $i$, com estoque inicial nulo. Desta forma, $\zeta_{i t}$ pode ser determinado recursivamente por:

$$
\zeta_{i t}= \begin{cases}\min _{\substack{0 \leq k<t \\ 1 \leq j \leq M}}\left\{\zeta_{i k}+\Gamma_{i j k t}\right\}, & \text { para } t=1, \ldots, T ; \\ 0, & \text { para } t=0 .\end{cases}
$$

A programação dinâmica recursiva, neste caso, também é equivalente ao problema de encontrar o caminho de custo mínimo em uma rede, em que cada nó corresponde a um período de tempo, e um arco $(k, t)$ está associado à produção de $d_{i k t}^{\prime}$ com custo $\Gamma_{i j k t}$. O algoritmo proposto tem complexidade $O\left(m T^{2}\right)$ e pode ser implementado de forma eficiente baseado em Evans (1985) e proposto por Armentano e Toledo (1997).

A fase construtiva foi realizada da seguinte maneira para cada item $i$ de 1 a $N$ e todo período $t$ de 1 a $T$ :

1. Seja $S$ o conjunto de todos os caminhos do período 1 ao $t$ calculados pelos valores de $\zeta_{i t}$ definidos na equação $(5.2)$, e seja $g(j, s)$ o custo $\zeta_{i s}+\Gamma_{i j s t}$, com $0 \leq s \leq t-1$ e $1 \leq j \leq M$.

2. Defina gmin e gmax como, respectivamente, os custos mínimo e máximo de $g(j, s)$, $\operatorname{com} 0 \leq s \leq t-1$ e $1 \leq j \leq M$.

3. Seja LRC a lista composta pelos elementos de $S$, tal que $g(j, s) \in[$ gmin,gmin + $\alpha(\operatorname{gmax}-\operatorname{gmin})]$, com $0 \leq s \leq t-1,1 \leq j \leq M, \alpha$ fixo no intervalo [0,1].

4. Sorteie um elemento da LRC.

Vale ressaltar que o algoritmo que calcula o $\zeta_{i t}$ é recursivo, sendo necessário o cálculo dos valores de $\zeta_{i t}$ dos períodos anteriores ao $t$. Note ainda que a cada período, o conjunto $S$ e a LRC são reconstruídos. Além disso, ao ser sorteado o elemento da LRC, o caminho escolhido será justamente a solução do período 1 ao $t$ factível para o problema não capacitado. 
Quanto ao parâmetro $\alpha$, observe que se ele assumir o valor 1, a LRC será justamente o conjunto $S$, o que implica em um sorteio de elementos totalmente aleatório. Por outro lado, se o parâmetro $\alpha$ assumir o valor 0, o único elemento que formará a LRC será o gmin, o que implica no algoritmo ótimo para o problema de máquinas paralelas não capacitado.

A solução final construída no período $T$ para todos os períodos é, na maioria das vezes, infactível para o CLSP com múltiplas plantas.

Um pseudocódigo deste procedimento é apresentado no Algoritmo 5, em que $i$ é um dos itens do horizonte de planejamento, Leia Entrada() é a função que lê o arquivo de dados de entrada e $g(s)$ é a função que calcula o valor da função objetivo do elemento $s$. Tal procedimento, como já foi dito, deve ser aplicado a todos os $N$ itens.

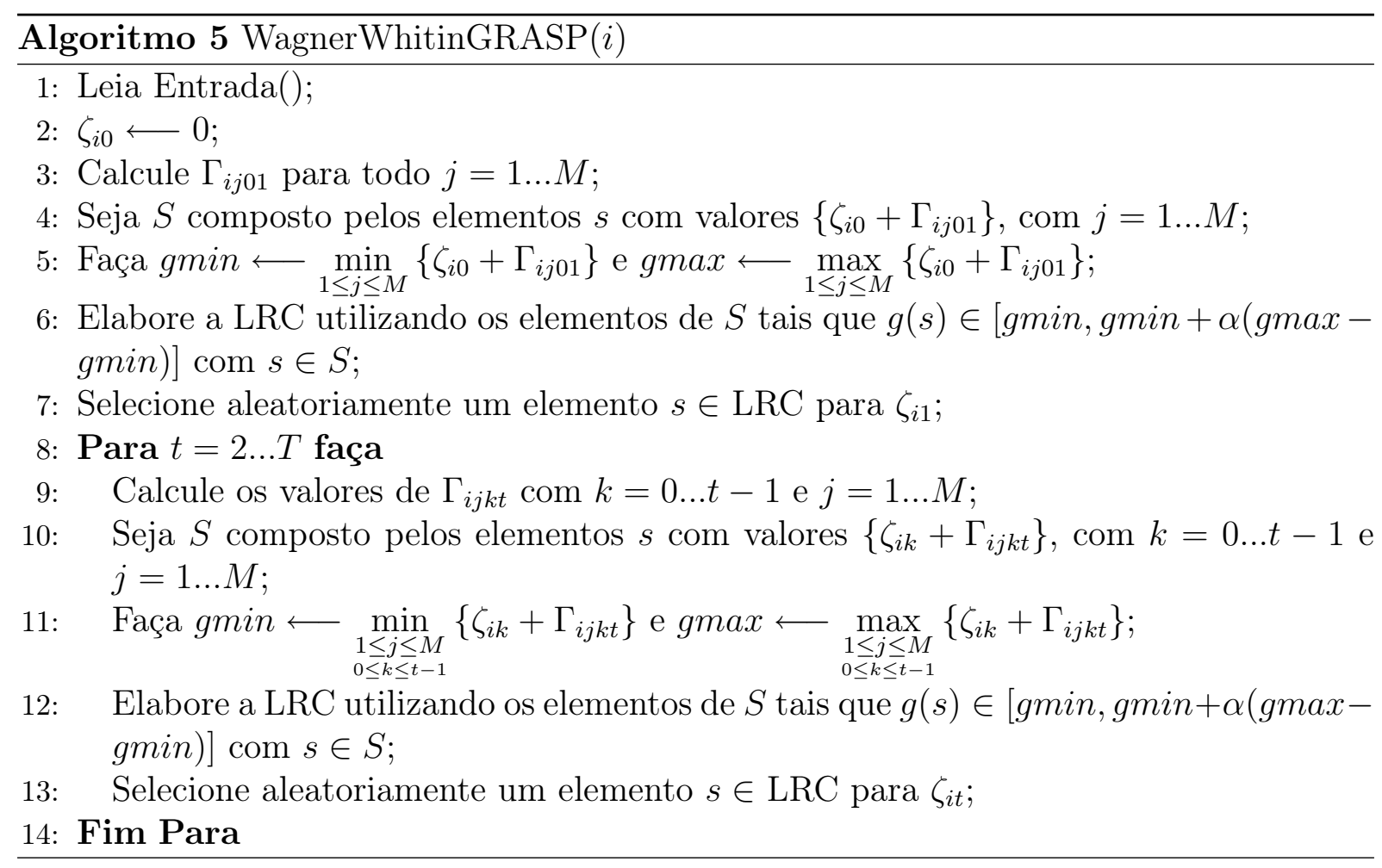

\subsubsection{Vizinhança da Busca}

Para realizar a busca local é necessário que se defina a sua vizinhança. Para tanto, foram estudadas as vizinhanças reportadas em Gopalakrishnan et al. (2001) que consistem de transferências de lotes de produção entre os períodos. Além disso, estes movimentos foram adaptados para o CLSP com múltiplas plantas. Tais movimentos foram propostos da maneira como é descrito a seguir:

LOT1 - Neste movimento, busca-se transferir uma certa quantidade de produção de um 
item $i$ no período $t$ na planta $j$, para um período anterior $s(1 \leq s \leq t-1)$ em alguma das plantas $k$ com $1 \leq k \leq M$, ou mesmo para o período $t$ em uma planta $k \neq j$. Esta quantidade transferida pode ser tanto o lote todo do item, quanto uma parte dele. A decisão de quanto se deve transferir é feita escolhendo-se aquela que resulte na maior economia dentre os seguintes valores:

- A quantidade total produzida do item $i$ no período $t$ na planta $j\left(x_{i j t}\right)$;

- O mínimo entre a quantidade total produzida do item $i$ no período $t$ na planta $j$ e a quantidade do item $i$ que, se transferir do período $t$ da planta $j$, acaba com o excesso de sua capacidade $\left(q_{\text {exc }}\right)$;

- O mínimo entre a quantidade total produzida do item $i$ no período $t$ na planta $j$ e a quantidade que pode ser produzida no período $s$ na planta $k$ que não viola sua capacidade disponível $\left(q_{\text {sobra }}\right)$.

No Algoritmo 6 este algoritmo está descrito de forma simplificada.

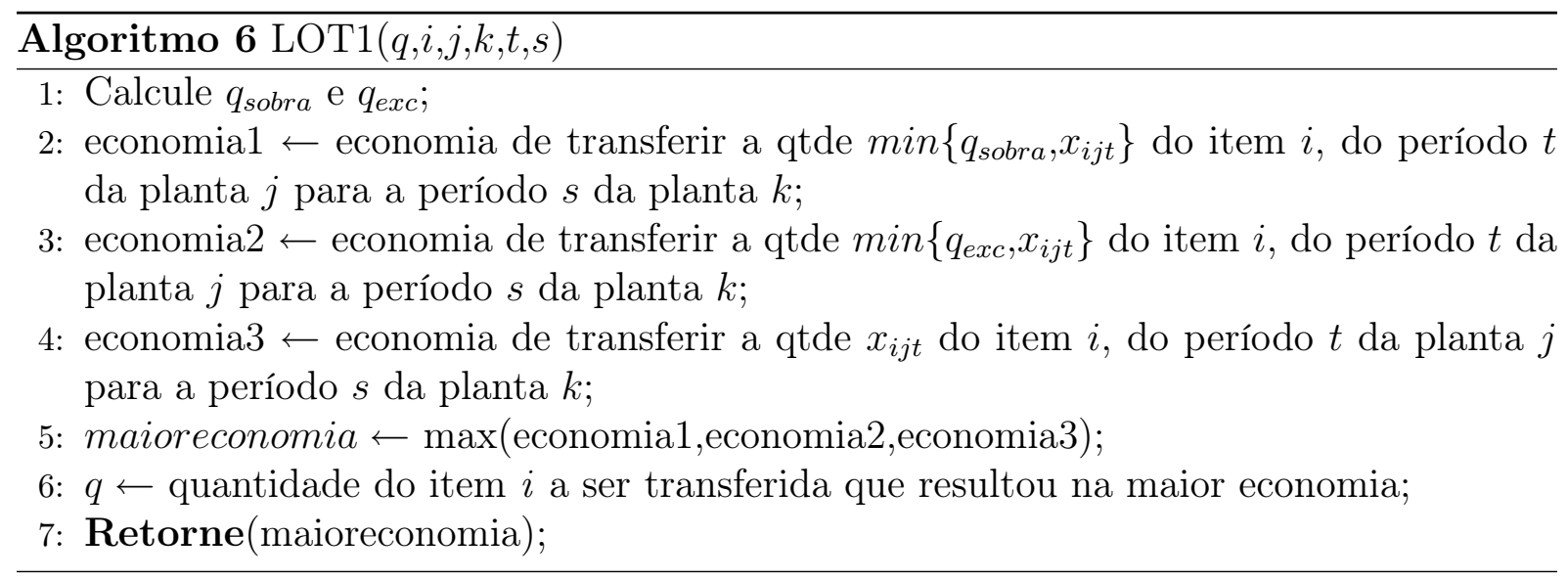

LOT2 - Esse movimento é semelhante ao anterior, no entanto, ao invés de antecipar um lote de produção, este é postergado, ou seja, parte de um lote ou o lote todo é transferido de um período $t$ da planta $j$ para um período posterior $t+1 \leq s \leq T$ e planta $1 \leq k \leq M$. Na execução deste movimento, deve-se tomar o cuidado de não deixar de atender a demanda, permitindo a transferência de no máximo o menor estoque entre todos os períodos que vão de $t$ a $s-1$ referente à produção do item $i$ no período $t$ na planta $j$. Defina este valor como Menor estoque. A decisão do quanto se transferir é feita escolhendo-se aquela que resulte na maior economia decorrente dos seguintes valores de transferências:

- O Menor estoque;

- O mínimo entre o Menor estoque e a quantidade do item $i$ que, se transferir do período $t$ da planta $j$, acabe com o excesso de sua capacidade $\left(q_{e x c}\right)$; 
- O mínimo entre o Menor estoque e a quantidade que pode ser produzida no período $s$ na planta $k$ que não viola sua capacidade disponível $\left(q_{\text {sobra }}\right)$.

No Algoritmo 7 este algoritmo está descrito de forma simplificada.

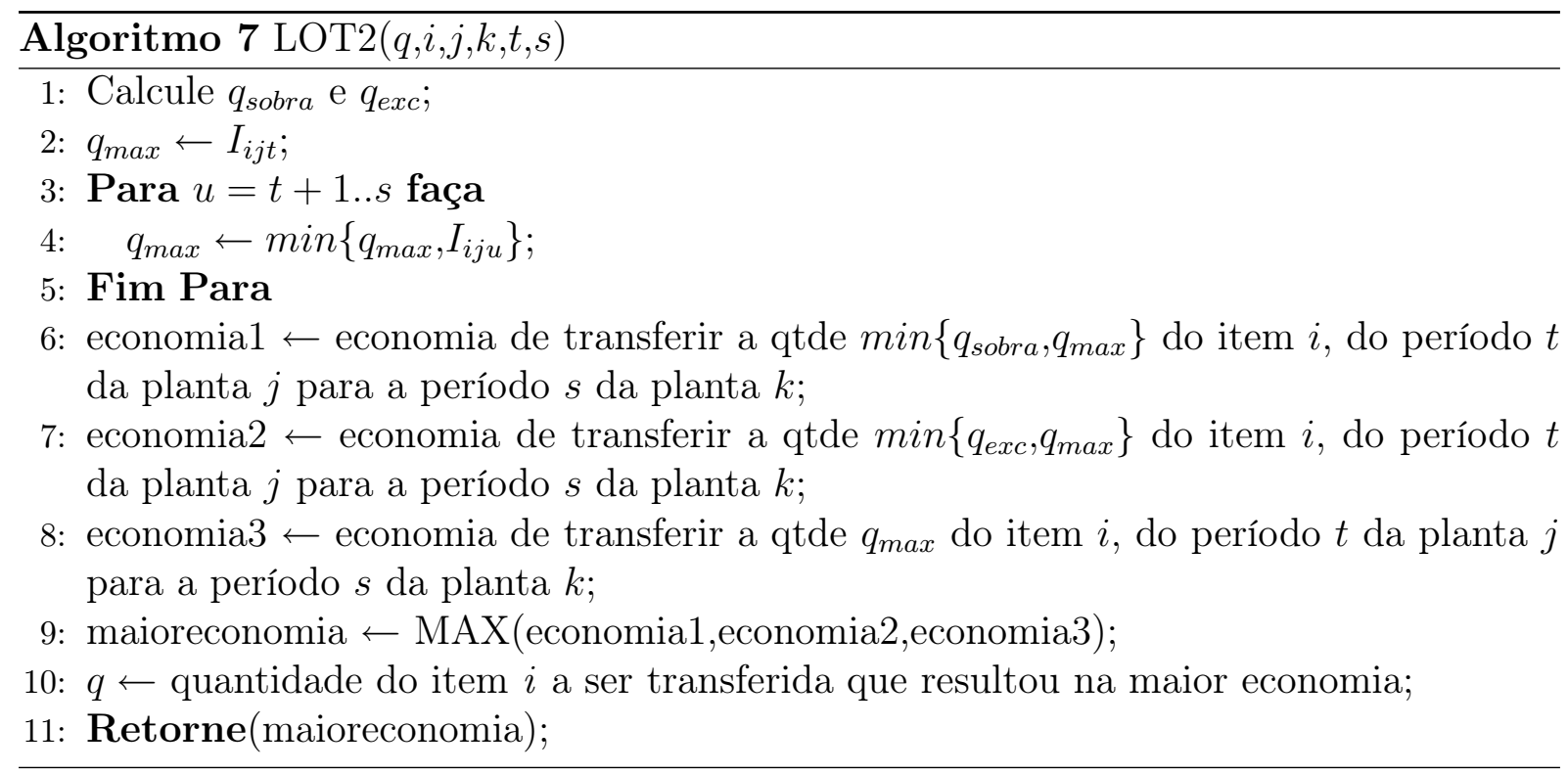

Pode-se pensar na possibilidade de nenhum dos movimentos gerar economia. Mas também é levado em consideração o fato da solução violar as restrições de capacidade, e sua infactibilidade deve ser reduzida. Tal violação é traduzida no valor da solução através de uma penalização, como definido em (5.3).

Solucao infactivel $=$ Valor da funcao objetivo $+p *$ Capacidade total violada

Esta penalização é usada quando a solução obtida apresenta violação de capacidade em um ou mais períodos. Logo, o valor da solução penalizada, ou seja, o valor da solução infactível corresponde ao valor da solução que não viole as restrições de capacidade, adicionada da capacidade violada em cada um dos períodos, multiplicada pelo valor da penalidade denotado por $p$. Para verificar se a solução atual é factível, basta verificar se o valor da solução com a penalização é igual ao sem penalização. O valor do parâmetro $p$ foi obtido experimentalmente, pois tem que ser compatível com os parâmetros dos problemas. Logo, ambos os movimentos, como se pode perceber, buscam encontrar uma solução factível, reduzindo a violação de capacidade e a melhoria no valor da função objetivo.

Como pode ser observado no Algoritmo 8, o método de busca local utilizado é o de máxima descida, ou seja, são analisadas todas as plantas, todos os itens e todos os períodos, para executar, a cada iteração da busca, o movimento que resulte na maior 


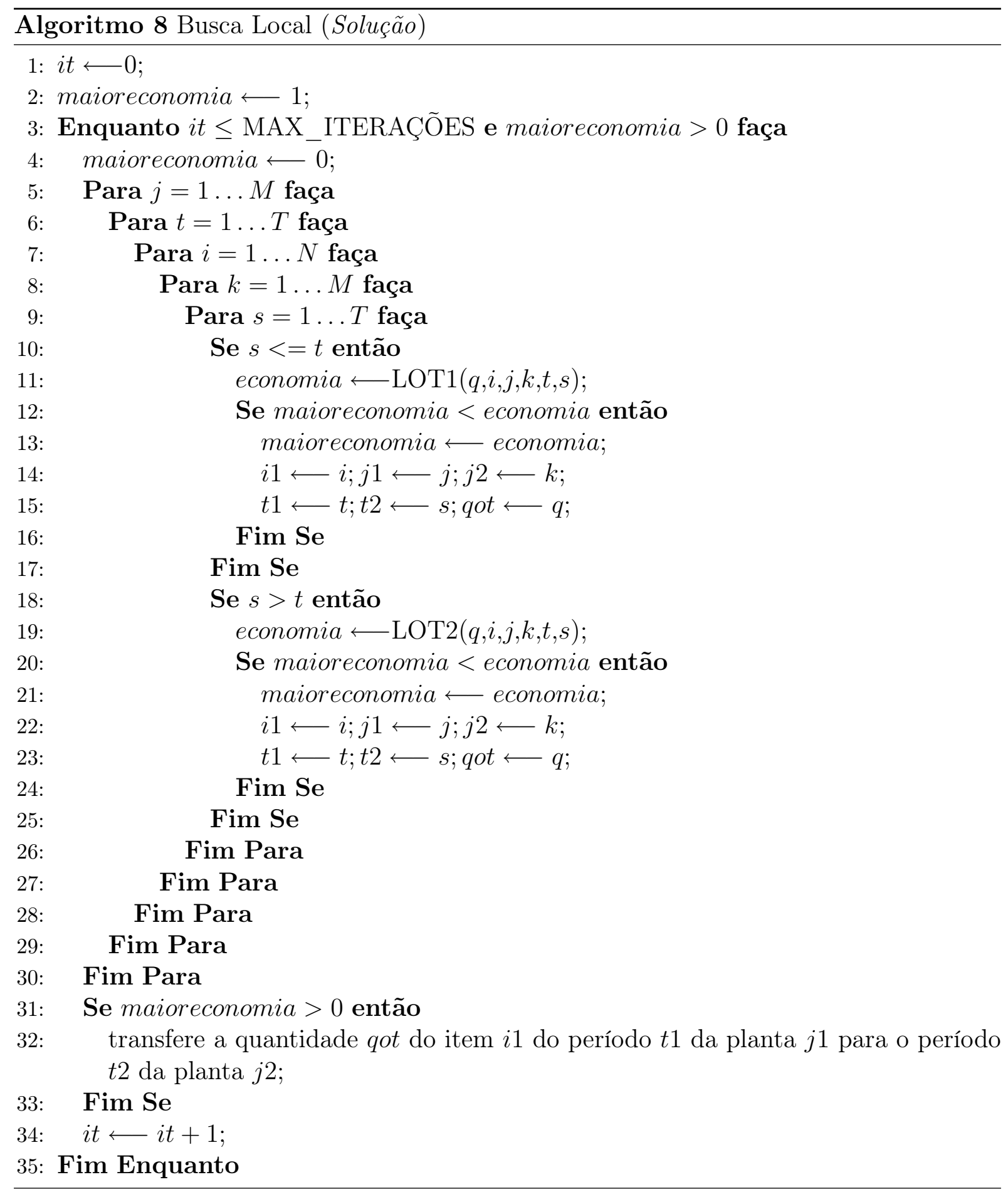

economia para a solução presente. O método da descida também foi testado, aquele em que se considera o primeiro movimento que melhore a solução atual, entretanto, testes computacionais mostraram que seu desempenho é pior que o método de máxima descida. Considere no Algoritmo 8, os parâmetros da Seção 3.1, os Procedimentos 6 e 7 e MAX_ITERAÇÕES, um número máximo de iterações.

No Algoritmo 9 é apresentado GRASP proposto. 


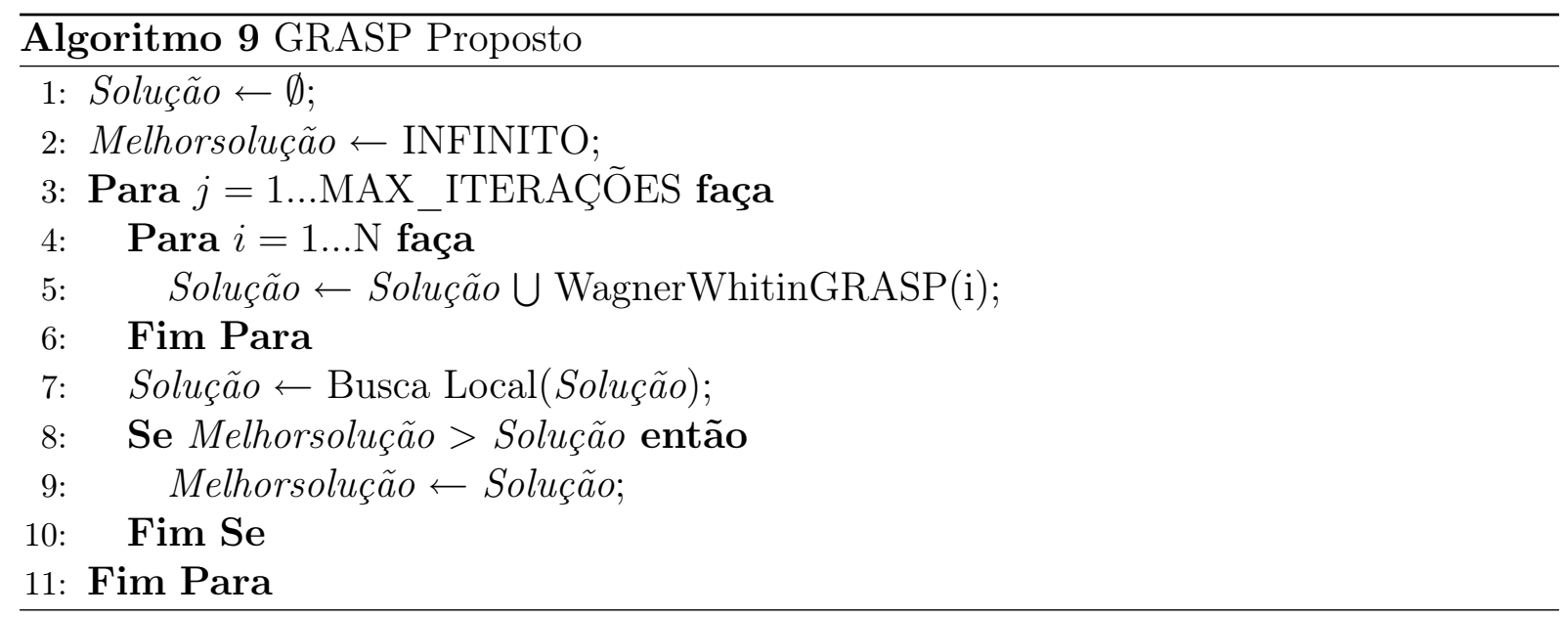

\subsubsection{Estratégia path relinking proposta}

A estratégia path relinking proposta armazena um número fixo de soluções de elite, que são as melhores soluções (factíveis) obtidas pelo GRASP. A partir destas soluções, a estratégia as combina duas a duas, indo sempre da solução de maior valor, solução inicial, para a de menor valor, solução guia. Tais combinações são feitas de acordo com o Algoritmo 10.

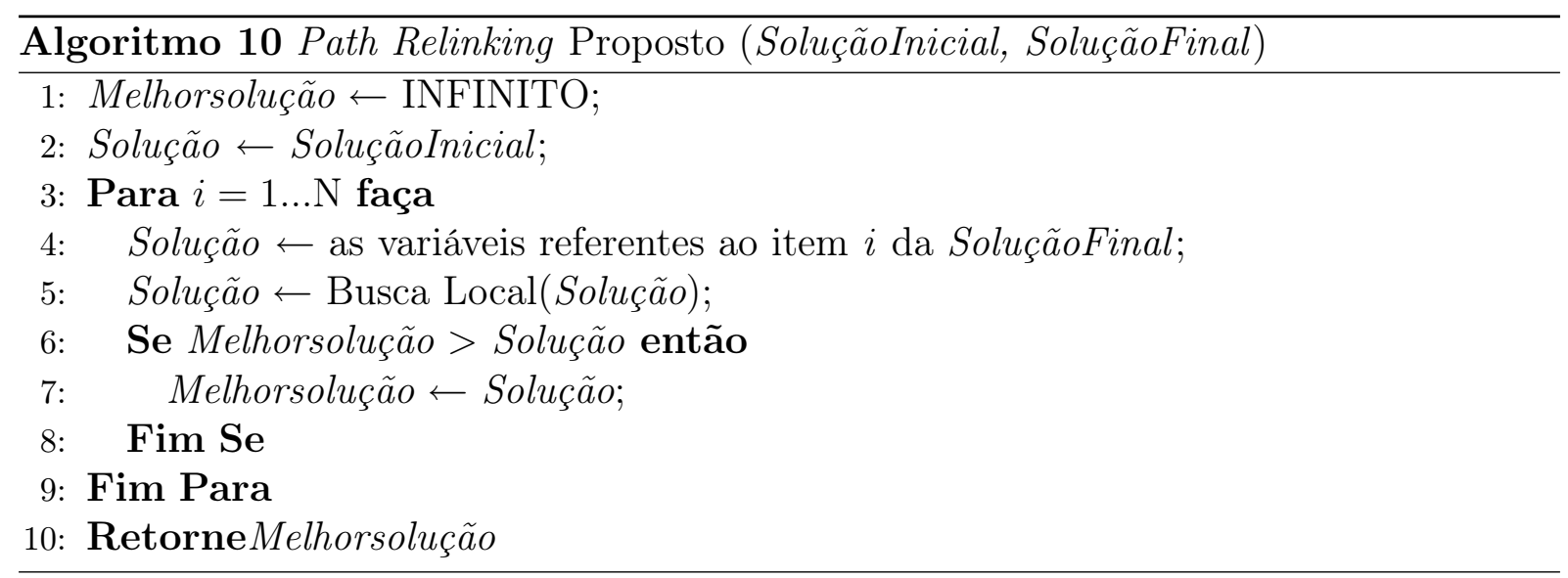

Pode-se observar que o número de iterações desta rotina é o número de itens. O que diferencia esta estratégia da estratégia original path relinking, é o fato desta aplicar a busca local na solução a cada iteração, mudando de solução no passo dado em direção à solução guia. Esta mudança de solução em dado passo não garante que no passo final a solução resultante seja a solução guia, ou seja, que seja a solução de elite de menor valor que participa da combinação. Além disso, foi testada uma estratégia com base na idéia original de path relinking em que as soluções, antes de passar pela busca local fossem armazenadas, para que estas fossem as soluções a serem atualizadas pelas variáveis do item da solução guia, garantindo que no final a solução guia fosse atingida. Entretanto, esta estratégia teve um considerável aumento de tempo de processamento com um gap médio maior ao desta estratégia proposta. 


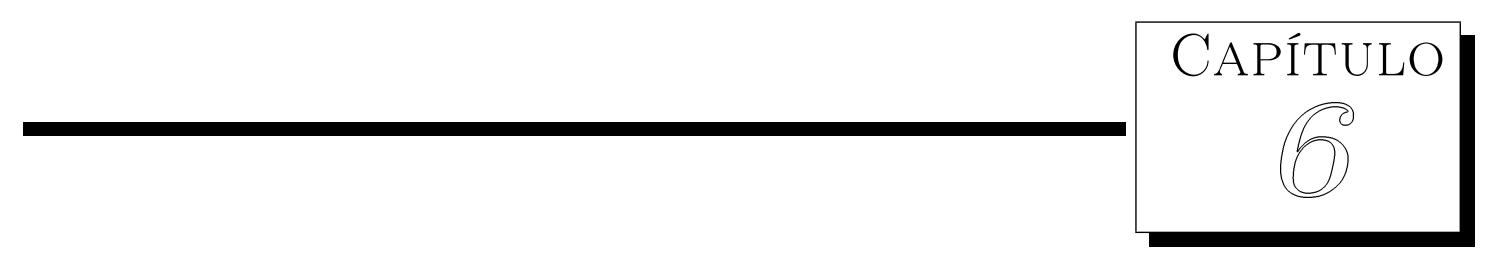

\section{Testes computacionais}

A meta-heurística proposta foi implementada em linguagem $\mathrm{C}$ e compilada no software Borland $\mathrm{C}++5.02$ usando o microcomputador AMD Athlon 64, de 1GB RAM e Sistema Operacional Windows. Os experimentos foram divididos em duas partes. Na primeira parte, a heurística é testada para o CLSP com múltiplas plantas usando as instâncias geradas por Sambasivan e Yahya (2005), e os resultados são comparados aos da heurística Lagrangiana destes autores e com os valores ótimos. Ainda nesta primeira parte, há outro experimento em que são utilizadas instâncias geradas com base em Toledo e Armentano (2006), o qual foi adaptado para ter transferências entre as plantas e múltiplos armazéns de estocagem. A segunda parte consiste em testar a meta-heurística usando as instâncias geradas por Toledo e Armentano (2006) para o CLSP com máquinas paralelas e comparar os resultados com os da heurística Lagrangiana proposta por eles. Além disso, análises estatísticas comparativas foram realizadas para verificar a eficiência das heurísticas comparadas às da literatura.

Os valores dos parâmetros da heurística proposta foram definidos de forma experimental como descrito nas próximas seções. Além disso, os testes foram executados 10 vezes para que a estabilidade com relação ao gap e tempo médios fossem avaliadas. No caso de máquinas paralelas, o pior tempo foi reportado, assim como em Toledo e Armentano (2006). No caso de múltiplas plantas, não foi necessário reportar o pior tempo, pois os tempos de solução das instâncias foram muito próximos da média.

Para verificar a eficiência do path relinking proposto, as instâncias foram executadas na meta-heurística sem este procedimento em uma primeira etapa. Na segunda etapa, 
os testes foram feitos considerando a fase de path relinking para avaliar a influência na meta-heurística. Para identificar as heurísticas, o GRASP puro será denominado Gheur, enquanto o GRASP com path relinking, será denominado GPRheur. Além disso, a heurística Lagrangiana de Sambasivan e Yahya (2005) será identificada por LRA.

\subsection{Testes com múltiplas plantas}

Esta primeira fase de testes é composta por dois experimentos em que para cada experimento são apresentadas as configurações dos testes com múltiplas plantas assim como os seus resultados.

\subsubsection{Experimento 1}

Neste experimento, os testes com múltiplas plantas foram os mesmos de Sambasivan e Yahya (2005), cedidos pelos autores. Os parâmetros das instâncias foram ajustados segundo uma distribuição uniforme definida em um intervalo [a, b] denotada por U[a, b], e os seus valores foram definidos como segue abaixo:

- custo unitário de produção $\left(c_{i j t}\right)$ : U[1.0, 8.0];

- custo unitário de preparação $\left(s_{i j t}\right)$ : 10;

- custo unitário de estoque $\left(h_{i j}\right)$ : U[0, 2.0];

- custo unitário de transferência $\left(r_{j k}\right)$ : U[0, 2.0];

- tempo unitário de processamento $\left(b_{i j t}\right): 1.0$

- tempo de preparação $\left(f_{i j}\right): 0.5$;

- demanda $\left(d_{i j t}\right): \mathrm{U}[0,50]$.

As classes de instâncias são compostas de todas as combinações de 3 e 4 plantas, de 3, 4, 5 e 6 períodos e de 5, 10 e 15 itens. Cada classe de instâncias é composta por 5 problemas e as capacidades das instâncias foram calculadas usando uma variável auxiliar reportada em Sambasivan e Yahya (2005) que é o CTR (capacity tighness ratio). Tal variável consiste, segundo Sambasivan e Schimidt (2002), da natureza da capacidade que é dita "apertada" ou não, ou seja, o quão significativa é a restrição de capacidade. Para cada planta, os autores definiram um valor de CTR sendo o valor inferior a 1.5 
considerado como capacidade apertada, e superior a este valor como não sendo apertada. A capacidade é calculada da seguinte forma:

$$
C_{j}=\left(\sum_{t=1}^{T} \sum_{i=1}^{N} \frac{b_{i j} d_{i j t}}{T}\right) C T R .
$$

Além disso, para avaliar a solução das heurísticas propostas, foi utilizada a solução ótima da relaxação linear das instâncias. O gap é calculado em (\%) como:

$$
G a p=\frac{\left(z_{h}-z_{l}\right)}{z_{l}} 100
$$

em que

$z_{h}$ : valor da solução da heurística;

$z_{l}$ : valor da solução da relaxação linear.

As classes de instâncias são definidas por: Número de plantas x Número de períodos x Número de itens. Por exemplo, a classe de instâncias composta por 3 plantas, 4 períodos e 10 itens é denominada $3 \times 4 \times 10$.

O número de soluções iniciais e o número máximo de iterações na fase de factibilidade são, respectivamente, 1000 e 100. O número de soluções de elite é 15 para os testes de múltiplas plantas. Estes parâmetros foram definidos experimentalmente.

A escolha dos parâmetros $\alpha$ e $p$ foi feita levando-se em conta alguns testes preliminares. Estes testes foram reportados na Tabela $6.1 \mathrm{em}$ que foram reportados o gap e o tempo médios de todas instâncias resultantes do GPRheur para estas instâncias descritas acima com diversos valores de $\alpha(0.3,0.4,0.5,0.6$ e 0.7$)$ e $p(25,50$ e 75$)$.

Tabela 6.1: Testes para escolha dos parâmetros $\alpha$ e $p$.

\begin{tabular}{l|l|l|l|l|l|l}
\cline { 3 - 7 } & \multicolumn{5}{c}{$\alpha$} \\
\hline $\mathbf{p}$ & Variáveis & $\mathbf{0 . 3}$ & $\mathbf{0 . 4}$ & $\mathbf{0 . 5}$ & $\mathbf{0 . 6}$ & $\mathbf{0 . 7}$ \\
\hline $\mathbf{2 5}$ & & 8.24 & 8.38 & 8.43 & 8.50 & 8.71 \\
$\mathbf{5 0}$ & Gap médio(\%) & 8.18 & 8.33 & 8.55 & 8.61 & 8.66 \\
$\mathbf{7 5}$ & & 8.25 & 8.40 & 8.54 & 8.62 & 8.71 \\
\hline $\mathbf{2 5}$ & & 11.86 & 12.48 & 13.36 & 13.52 & 13.86 \\
$\mathbf{5 0}$ & Tempo médio (s) & 11.93 & 12.1 & 14.20 & 14.28 & 14.68 \\
$\mathbf{7 5}$ & & 12.17 & 12.93 & 13.52 & 14.04 & 14.92 \\
\hline
\end{tabular}

Note que quanto maior é o valor de $\alpha$, maior é o tempo médio, e maior é o gap médio. Por este motivo, foi escolhido o menor valor de $\alpha$, ou seja, 0.3. Quanto ao valor do parâmetro $p$, foi observado que há uma maior estabilidade entre os valores. Entretanto, 
para o $p$ foi escolhido o valor que resultou no menor gap com relação ao $\alpha 0.3$, ou seja, 50.

Na Tabela 6.2 estão reportados os resultados do Gheur, GPRheur e LRA. Considere GM e TM, respectivamente, os gaps e tempos médios correspondentes a cada classe de instância, relativos às heurísticas indicadas. Considere ainda na Tabela 6.2, o CTR médio de cada classe de instâncias, ajustado por Sambasivan e Yahya (2005).

Tabela 6.2: Resultados do Experimento 1.

\begin{tabular}{l|cc|cc|cc}
\multicolumn{2}{r|}{} & \multicolumn{2}{c|}{ LRA } & \multicolumn{2}{c|}{ Gheur } & \multicolumn{2}{c}{ GPRheur } \\
\hline Classe & GM & TM & GM & TM & GM & TM \\
\hline $3 \times 3 \times 5$ & 7.08 & 7.66 & 7.96 & 0.84 & $\mathbf{6 . 9 0}$ & 0.85 \\
$3 \times 3 \times 10$ & 12.14 & 13.46 & 6.70 & 1.80 & $\mathbf{5 . 6 5}$ & 2.08 \\
$3 \times 3 \times 15$ & 15.31 & 11.6 & 8.08 & 3.43 & $\mathbf{6 . 5 4}$ & 4.06 \\
$3 \times 4 \times 5$ & 7.50 & 4.4 & 7.62 & 1.54 & $\mathbf{6 . 5 2}$ & 1.76 \\
$3 \times 4 \times 10$ & 11.71 & 31.04 & 7.04 & 4.34 & $\mathbf{5 . 8 4}$ & 4.52 \\
$3 \times 4 \times 15$ & 13.38 & 21.22 & 9.60 & 6.86 & $\mathbf{7 . 6 9}$ & 8.94 \\
$3 \times 5 \times 5$ & 13.92 & 3.68 & 10.10 & 2.63 & $\mathbf{7 . 8 6}$ & 3.06 \\
$3 \times 5 \times 10$ & 10.19 & 3.42 & 10.56 & 7.27 & $\mathbf{8 . 4 9}$ & 8.57 \\
$3 \times 5 \times 15$ & 11.72 & 15.76 & 11.64 & 12.13 & $\mathbf{9 . 1 5}$ & 14.55 \\
$3 \times 6 \times 5$ & 8.16 & 13.62 & 9.62 & 4.08 & $\mathbf{7 . 6 9}$ & 4.64 \\
$3 \times 6 \times 10$ & 9.16 & 11.76 & 12.19 & 12.91 & 9.64 & 15.20 \\
$3 \times 6 \times 15$ & 9.62 & 17.68 & 12.35 & 20.73 & 10.67 & 23.82 \\
$4 \times 3 \times 5$ & 6.08 & 8.95 & 7.25 & 1.25 & 6.28 & 1.50 \\
$4 \times 3 \times 10$ & 11.26 & 11.74 & 7.67 & 3.08 & $\mathbf{6 . 2 6}$ & 3.88 \\
$4 \times 3 \times 15$ & 7.09 & 10.94 & 10.22 & 5.97 & 7.76 & 7.76 \\
$4 \times 4 \times 5$ & 8.79 & 6.3 & 8.98 & 2.50 & $\mathbf{7 . 6 7}$ & 2.95 \\
$4 \times 4 \times 10$ & 9.17 & 27.1 & 9.58 & 7.05 & $\mathbf{7 . 9 2}$ & 8.57 \\
$4 \times 4 \times 15$ & 10.66 & 33.54 & 11.46 & 14.68 & $\mathbf{9 . 2 9}$ & 18.00 \\
$4 \times 5 \times 5$ & 8.16 & 24.62 & 11.34 & 4.68 & 9.20 & 5.76 \\
$4 \times 5 \times 10$ & 7.09 & 33.14 & 11.88 & 13.72 & 9.21 & 17.96 \\
$4 \times 5 \times 15$ & 8.67 & 20.56 & 12.73 & 26.61 & 9.47 & 33.05 \\
$4 \times 6 \times 5$ & 7.11 & 29.68 & 11.11 & 6.16 & 9.09 & 7.65 \\
$4 \times 6 \times 10$ & 8.09 & 30.92 & 13.73 & 24.23 & 9.81 & 29.17 \\
$4 \times 6 \times 15$ & 10.07 & 46.1 & 15.94 & 47.56 & 11.81 & 57.75 \\
\hline Médias & 9.67 & 18.30 & 10.22 & 9.84 & $\mathbf{8 . 1 8}$ & 11.93 \\
\hline
\end{tabular}

Neste experimento, todas as heurísticas (propostas e da literatura) atingiram 100\% de factibilidade. Na Tabela 6.2, pode ser observado que além do GPRheur ter apresentado um número maior de classes com gap médio melhor se comparado com a LRA, totalizando 14 (em negrito), o gap médio dentre todas as classes foi também inferior, com um valor de $8.18 \%$ contra $9.67 \%$ da literatura. 
Pode-se observar que apesar dos resultados do Gheur serem competitivos, pois houve 7 classes de instâncias das 24 em que o gap médio foi inferior aos da literatura, o gap médio de todas as classes de $10.22 \%$ é superior à LRA.

Além disso, ambas as heurísticas GRASP obtiveram tempos médios consideravelmente inferior ao da heurística lagrangiana da literatura.

\subsubsection{Experimento 2}

As 120 instâncias que compõem cada uma das 8 classes desta fase de testes consistem de todas as combinações das mesmas dimensões das instâncias do Experimento 1, em que cada combinação é composta por 5 instâncias. Os parâmetros destas instâncias foram gerados seguindo uma distribuição uniforme em um intervalo [a, b], que consiste de:

- custo de produção unitário $\left(c_{i j}\right)$ : U[1.5, 2.5];

- custo de preparação $\left(s_{i j}\right)$ : U[5.0, 95.0], custos de preparação baixos e altos são gerados neste intervalo, entretanto, o valor obtido para o alto custo de preparação é multiplicado por 10 no final;

- custo unitário de estoque $\left(h_{i j}\right)$ : U[0.2, 0.4$]$;

- custo unitário de transferência $\left(r_{j k}\right)$ : U[0.2, 0.4];

- tempo de processamento unitário $\left(b_{i j}\right)$ : U[1.0, 5.0];

- tempo de preparação $\left(f_{i j}\right)$ : U[10.0, 50.0], tempos de preparação baixos e altos são gerados neste intervalo, entretanto, o valor obtido para o alto tempo de preparação é multiplicado por 1.5 no final;

- demanda $\left(d_{i j t}\right): \mathrm{U}[0,180]$.

As capacidades foram geradas de acordo com a seguinte formulação matemática. Seja $C a p[j]$ a capacidade do problema.

$$
C a p[j]=\left[\sum_{t=1}^{T} \sum_{i=1}^{N} \frac{\left(d_{i j t} b_{i j}+f_{i j}\right)}{T}\right] .
$$

Cada classe é definida de acordo com a capacidade que é normal ou apertada, obtida pela equação (6.3) multiplicada por, respectivamente, 1.0 e 0.9; como o custo de preparação (alto ou baixo); e com o tempo de preparação (alto ou baixo). Para identificar cada 
classe de instâncias, foi utilizada uma nomenclatura de acordo com estes parâmetros. Considere capacidade/custo de preparação/tempo de preparação: (N) Normal; (A) Apertada; (B) Baixo; (A) Alto. Então, por exemplo, a classe de instâncias com capacidade normal, baixo custo de preparação e alto tempo de preparação é denotado por NBA.

Para avaliar os resultados da solução, o limitante inferior usado é a solução resultante da relaxação linear e o cálculo do gap para cada instância é como segue (\%):

$$
\text { Gap }=\frac{\left(z_{h}-z_{l}\right)}{z_{l}} 100
$$

com

$z_{h}$ : valor da solução da heurística;

$z_{l}$ : valor do limitante inferior.

O número de soluções iniciais para as instâncias foi 1000 e, ao se inserir a estratégia de path relinking, o número de soluções de elite considerado é 15.

Na Tabela 6.3, GM e TM correspondem, respectivamente, aos gaps e tempos médios. Além disso, FAC indica a porcentagem de soluções factíveis encontradas pelas heurísticas. As médias de cada coluna da tabela foram reportadas em separado para as classes com alto custo de preparação e com baixo custo de preparação. Na última linha, as médias de todas as classes são reportadas.

Tabela 6.3: Resultados do Experimento 2.

\begin{tabular}{lccc|cc}
\cline { 3 - 6 } & \multicolumn{2}{c|}{ Gheur } & \multicolumn{2}{c}{ GPRheur } \\
\hline Classe & FAC & GM & TM & GM & TM \\
\hline AAA & 97.5 & 30.3 & 5.8 & 28.4 & 7.7 \\
NAB & 99.1 & 27.7 & 6.0 & 26.1 & 10.7 \\
AAB & 97.5 & 31.4 & 5.4 & 29.8 & 7.5 \\
NAA & 100 & 26.7 & 6.0 & 25.3 & 7.2 \\
\hline Médias & 98.5 & 29.0 & 5.8 & 27.4 & 8.3 \\
\hline NBB & 100 & 8.7 & 17.8 & 8.2 & 21.2 \\
ABA & 99.1 & 9.5 & 15.8 & 8.8 & 17.4 \\
ABB & 98.3 & 9.8 & 15.0 & 9.0 & 16.8 \\
NBA & 100 & 8.6 & 17.5 & 8.1 & 25.9 \\
\hline Médias & 99.4 & 9.1 & 16.5 & 8.5 & 20.3 \\
\hline Médias & 98.9 & 19.1 & 11.2 & 17.9 & 14.3 \\
\hline
\end{tabular}

Note pela Tabela 6.3 que as classes de instâncias com baixo custo de preparação têm o gap médio aproximado do valor do gap médio do experimento reportado na Tabela 6.2. Com relação às classes de instâncias com alto custo de preparação pode-se observar um 
aumento considerável dos gaps médios, que é provavelmente conseqüência do problema linear ter valores pequenos para as variáveis $y$, resultando em um limitante inferior "pobre". Como é apresentado na Seção 4.3, não foi possível obter a solução ótima para todos estes problemas em tempo computacional aceitável, o que afirma a utilidade da heurística. Além disso, a média de utilização de capacidade de ambas heurísticas para as classes de instâncias é similar: $85.2 \%$ e $78.8 \%$ para as instâncias com baixos e altos custos de preparação, respectivamente, $85.6 \%$ de uso da capacidade nas instâncias com capacidade restrita, e $79.1 \%$ para instâncias com capacidade normal.

\subsection{Testes com máquinas paralelas}

Nesta segunda etapa, são detalhados os testes para o CLSP com máquinas paralelas. As instâncias para estes testes são configuradas segundo Toledo e Armentano (2006).

\subsubsection{Configuração das instâncias}

As 2880 instâncias que compõem esta fase de testes consistem de todas as combinações de 6, 12, 25 e 50 itens; 2, 4 e 6 máquinas; e 6, 12 e 18 períodos. Cada combinação é composta por 10 instâncias. Os parâmetros destas instâncias foram gerados seguindo uma distribuição uniforme em um intervalo [a, b] denotado por U[a, b], que consiste de:

- custo de produção unitário $\left(c_{i j}\right)$ : U[1.5, 2.5];

- custo de preparação $\left(s_{i j}\right)$ : U[5.0, 95.0], custos de preparação baixos e altos são gerados neste intervalo, entretanto, o valor obtido para o alto custo de preparação é multiplicado por 10 no final;

- custo unitário de estoque $\left(h_{i}\right)$ : U[0.2, 0.4];

- tempo de processamento unitário $\left(b_{i j}\right)$ : U[1.0, 5.0];

- tempo de preparação $\left(f_{i j}\right)$ : U[10.0, 50.0], tempos de preparação baixos e altos são gerados neste intervalo, entretanto, o valor obtido para o alto tempo de preparação é multiplicado por 1.5 no final;

- demanda $\left(d_{i t}\right)$ : U[0, 180].

As capacidades foram geradas de acordo com a seguinte formulação matemática obtida através de uma regressão linear, como descrito em Toledo e Armentano (2006). Seja Cap a capacidade do problema. 


$$
\text { Cap }=\left[\sum_{t=1}^{T} \sum_{j=1}^{M} \sum_{i=1}^{N} \frac{\left(\frac{d_{i t}}{M} b_{i j}+f_{i j}\right)}{M T}\right](1.18-0.07 M) .
$$

Defina capacidades normal e apertada como sendo o valor resultante da equação (6.5) multiplicado por, respectivamente, 1.0 e 0.9. Para identificar as classes, considere a mesma nomenclatura da Seção 6.1.2.

Para avaliar os resultados da solução, o limitante inferior usado é a solução resultante da relaxação das restrições de capacidade (problema lagrangiano), e o cálculo do gap para cada instância é como segue (\%):

$$
\text { Gap }=\frac{\left(z_{h}-z_{l}\right)}{z_{l}} 100
$$

com

$z_{h}$ : valor da solução da heurística;

$z_{l}$ : valor do limitante inferior.

O número de soluções iniciais para as instâncias de máquinas paralelas variam de acordo com o número de itens. Para as instâncias com 6 itens foram ajustadas 40 iterações, 30 iterações para as instâncias com 12 itens, 20 iterações para as instâncias com 25 itens e 10 iterações para as instâncias com 50 itens. Além disso, ao inserir a estratégia de path relinking, o número de soluções de elite considerado é 5. Apenas nestes testes, o de máquinas paralelas, quando a meta-heurística não consegue obter uma solução factível para alguma das instâncias, é aplicada a fase de factibilização de Toledo e Armentano (2006) que é descrita no Apêndice A.

Tabela 6.4: Resultados para o CLSP com máquinas paralelas.

\begin{tabular}{l|rrrr|rrrr|rrr}
\cline { 2 - 11 } & \multicolumn{4}{c|}{ LRA } & \multicolumn{4}{c|}{ Gheur } & \multicolumn{3}{c}{ GPRheur } \\
\hline Classe & FAC & GM & TM & MaxT & FAC & GM & TM & MaxT & GM & TM & MaxT \\
\hline AAA & 96 & 23.5 & 8.4 & 95.5 & 98 & 18.8 & 6.1 & 56.2 & 14.5 & 11.0 & 115.8 \\
NAB & 99 & 11.7 & 5.3 & 49.7 & 99 & 18.2 & 7.0 & 76.1 & 14.0 & 11.4 & 133.9 \\
AAB & 98 & 18.5 & 7.8 & 108.1 & 94 & 27.1 & 10.0 & 101.3 & 21.2 & 17.0 & 187.5 \\
NAA & 98 & 13.8 & 5.9 & 62.3 & 100 & 12.9 & 4.8 & 46.3 & 9.9 & 9.0 & 95.5 \\
NBB & 99 & 2.0 & 3.9 & 70.9 & 98 & 2.8 & 13.1 & 136.0 & 2.2 & 17.3 & 179.2 \\
ABA & 95 & 4.2 & 14.4 & 631.7 & 97 & 3.1 & 13.1 & 130.6 & 2.5 & 18.2 & 182.8 \\
ABB & 98 & 3.4 & 8.9 & 183.5 & 90 & 4.4 & 13.4 & 147.5 & 3.5 & 19.8 & 220.0 \\
NBA & 98 & 2.5 & 4.9 & 48.8 & 100 & 1.7 & 12.0 & 116.3 & 1.3 & 15.8 & 159.0 \\
\hline Médias & 97.6 & 10.0 & 7.4 & 156.3 & 97.0 & 11.1 & 9.9 & 101.3 & $\mathbf{8 . 6}$ & 14.9 & 159.2 \\
\hline
\end{tabular}


Na Tabela 6.4 são reportados os resultados dos testes para o CLSP com máquinas paralelas. A primeira coluna corresponde às classes de instâncias, e as três outras colunas consistem, respectivamente, dos resultados da heurística Lagrangiana de Toledo e Armentano (2006) denotado por LRA, dos resultados do Gheur e dos resultados do GPRheur. As colunas FAC, GM, TM e MaxT indicam, respectivamente, a taxa de factibilidade em porcentagem, o gap médio em porcentagem, o tempo médio em segundos e o tempo máximo em segundos, tendo em vista que todas consideram as 10 execuções das classes de instâncias (cada classe possui 360 instâncias).

Pode-se observar pela Tabela 6.4, que ao se comparar os resultados da taxa de factibilidade (FAC) das heurísticas propostas com os da literatura, que as heurísticas propostas são competitivas, pois a heurística Lagrangiana tem uma média de 97.6\%, enquanto as heurísticas propostas têm $97 \%$ de factibilidade. Tendo em vista o tempo médio, o Gheur tem um tempo médio de 8.5 segundos que é um pouco inferior ao do GPRheur, que apresentou um tempo médio de 14.5 segundos. A heurística Lagrangiana apresentou um tempo médio menor com o valor de 7.4 segundos. Além disso, pode-se observar que o impacto do path relinking no gap médio é significativo, mudando o valor do gap médio do Gheur de $11.1 \%$ para $8.6 \%$ quando se adiciona a estratégia de path relinking. O valor do gap médio da heurística Lagrangiana é de 10\%, sendo intermediário aos da heurísticas propostas, pois é um valor melhor ao do Gheur e inferior ao do GPRheur.

Note ainda que para as classes de instâncias com alto tempo de preparação, o Gheur e o GPRheur apresentaram os melhores gaps, enquanto para as classes de instâncias com baixo tempo de preparação, a heurística Lagrangiana, ou seja, a LRA, obteve melhores resultados.

\subsection{Análise Estatística}

Depois de analisar os dados como foi feito anteriormente, achou-se interessante inferir sobre os dados comparados à literatura, para verificar se há diferença significante entre os valores. No caso dos testes com máquinas paralelas da Seção 6.2, as classes de instâncias foram separadas em grupos, e foram feitas algumas inferências sobre os dados, além de fazer a análise conjunta.

As variáveis analisadas foram os gaps médios no caso de múltiplas plantas, e gaps e tempos médios no de máquinas paralelas. Os testes foram realizados com as heurísticas duas a duas, ou seja, compara-se a heurística da literatura, LRA, com o Gheur, a LRA e o GPRheur e o Gheur com o GPRheur. Mais detalhes sobre os testes estatísticos são reportados no Apêndice B. Considere nas Tabela 6.5 e 6.6 signif. a abreviação de significativamente. 


\section{Testes com múltiplas plantas}

Neste conjunto de testes foi utilizado o teste t-Student pareado. Como neste caso, o número de pares a serem comparados é maior e os dados têm distribuição normal, podese usar este teste paramétrico. Na Tabela 6.5, a coluna Resultado indica o que concluiu a comparação dos gaps médios do primeiro elemento com o segundo elemento. Por exemplo, o Resultado de GPRheur $x$ LRA, indica o que se concluiu dos testes estatísticos dos gaps médios do GPRheur com relação a LRA.

Tabela 6.5: Resultados estatísticos para múltiplas plantas.

\begin{tabular}{l|l}
\hline Comparações & Resultado \\
\hline GPRheur $x$ LRA & signif. melhor \\
Gheur $x$ LRA & não é signif. pior \\
GPRheur $x$ Gheur & signif. melhor \\
\hline
\end{tabular}

Pode-se observar pela Tabela 6.5 que o GPRheur apresentou gaps médios significativamente inferiores aos da literatura. Comparando as heurísticas propostas entre si, os gaps médios do GPRheur foram significativamente inferiores aos do Gheur, enquanto o Gheur obteve gaps médios não significativamente superiores aos da LRA. Com estes testes, confirma-se o melhor desempenho da heurística GRASP comparando-se com a literatura.

\section{Testes para máquinas paralelas}

Neste caso, foi realizado o teste de Wilcoxon, pois os pares a serem comparados são poucos havendo a necessidade de um teste não paramétrico. Neste caso, considere o Grupo 2 grupo dos testes com máquinas paralelas contém as classes de instâncias com baixo tempo de preparação, o segundo grupo é composto pelas classes de instâncias com alto tempo de preparação (Grupo 2) e o último grupo é composto por todas as classes de instâncias (Grupo 3).

Pode-se concluir através dos testes estatísticos, que no caso de máquinas paralelas, as três heurísticas (propostas e da literatura) são bastante competitivas se todas as classes forem consideradas. Tendo em vista os resultados do Gheur e do GPRheur, o GPRheur obteve melhores gaps médios apesar dos tempos médios maiores. 
Tabela 6.6: Resultados estatísticos para máquinas paralelas.

\begin{tabular}{l|l|l|l}
\hline Grupos & Comparações & Gaps médios & Tempos médios \\
\hline \multirow{3}{*}{ Grupo 1 } & Gheur $x$ LRA & inconclusivo & inconclusivo \\
& GPRheur x LRA & inconclusivo & inconclusivo \\
& GPRheur $x$ Gheur & inconclusivo & inconclusivo \\
\hline \multirow{3}{*}{ Grupo 2 } & Gheur $x$ LRA & inconclusivo & inconclusivo \\
& GPRheur $x$ LRA & inconclusivo & inconclusivo \\
& GPRheur $x$ Gheur & inconclusivo & inconclusivo \\
\hline \multirow{3}{*}{ Grupo 3 } & Gheur $x$ LRA & não signif. pior & não signif. superior \\
& GPheur $x$ LRA & não signif. melhor & signif. superior \\
& GPRheur $x$ Gheur & signif. melhor & signif. superior \\
\hline
\end{tabular}





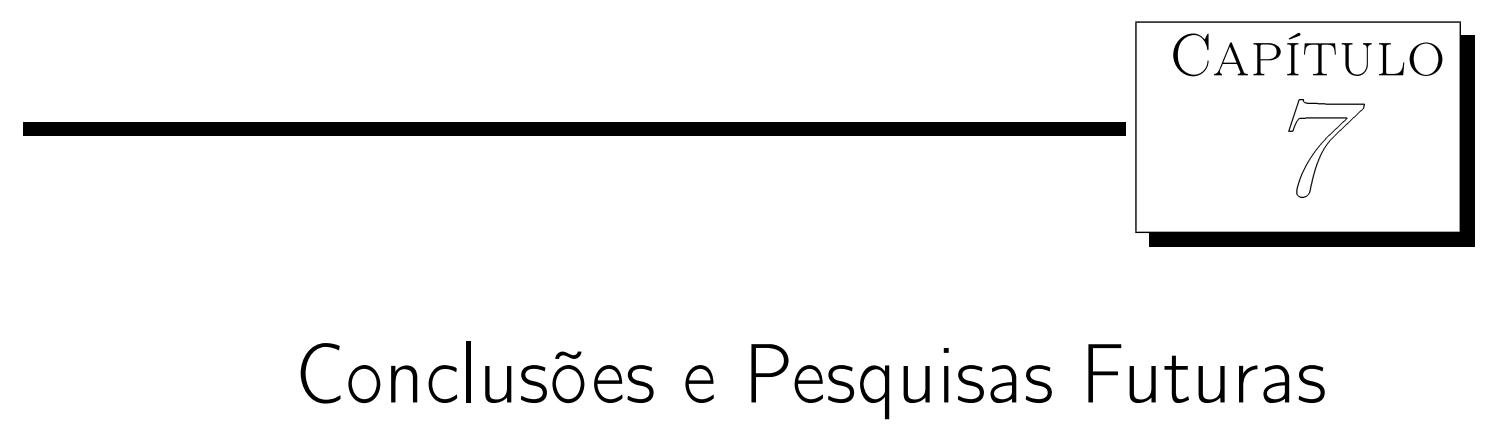

Nesta dissertação, foi abordado o CLSP com múltiplas plantas que consiste em planejar a produção de diversas fábricas que fornecem todas os mesmos itens. Estas plantas têm demanda própria e as transferências entre si são permitidas segundo um certo custo. Além disso, para cada planta há um armazém de estoque, o que origina vários armazéns de estoque com custos variados. Para resolver este problema foi usada inicialmente uma meta-heurística GRASP à qual, posteriormente, foi incorporada uma estratégia de path relinking.

As meta-heurísticas propostas foram bem sucedidas como os testes computacionais indicaram e superaram a heurística lagrangiana da literatura proposta por Sambasivan e Yahya (2005) confirmada por testes estatísticos. Além disso, os testes com máquinas paralelas possibilitaram um estudo mais detalhado destas heurísticas, indicando a qualidade da meta-heurística para a solução de outros tipos de problemas. Estas heurísticas podem inclusive ser testadas para vários outros tipos de problemas de dimensionamento de lotes.

O fato do problema de dimensionamento de lotes capacitado com tempo de preparação ser NP-difícil cria dificuldades na descoberta de soluções factíveis. Por este motivo, tiveram de ser buscados novos caminhos para fazer com que as meta-heurísticas estudadas e propostas nesta dissertação obtivessem sucesso. Algumas contribuições relevantes neste sentido foram propostas nesta dissertação e citadas a seguir:

- Uma nova abordagem da meta-heurística GRASP em que a solução resultante da fase construtiva não é factível, cabendo à busca local a tarefa de factibilização; 
- A proposta baseada em path relinking que até então não havia sido explorada para o problema de dimensionamento de lotes.

Quanto aos resultados, verifica-se que o GRASP puro obteve soluções competitivas com as da literatura, tanto nos testes com máquinas paralelas, quanto nos testes com múltiplas plantas. Ao se incorporar a estratégia path relinking ao GRASP, foram obtidas soluções de melhor qualidade e com resultados que superaram os da literatura. Logo, ambas as heurísticas propostas neste projeto são importantes métodos de solução para o problema de dimensionamento de lotes em máquinas paralelas e para o problema de dimensionamento de lotes em múltiplas plantas.

Vale a pena citar que nos testes de múltiplas plantas, em $90.6 \%$ o path relinking melhorou a solução do GRASP puro, e que apenas $7.0 \%$ dos casos, a solução final do path relinking convergiu para a solução guia.

Como pesquisa futura pode-se pensar em acoplar o CLSP com múltiplas plantas e o CLSP com máquinas paralelas que resulta em um problema NP-difícil, e desenvolver um método de solução para este. Além disso, no próprio CLSP com múltiplas plantas, pode-se inserir o setup carry over para avaliar o comportamento desta estratégia para este tipo de problema. 


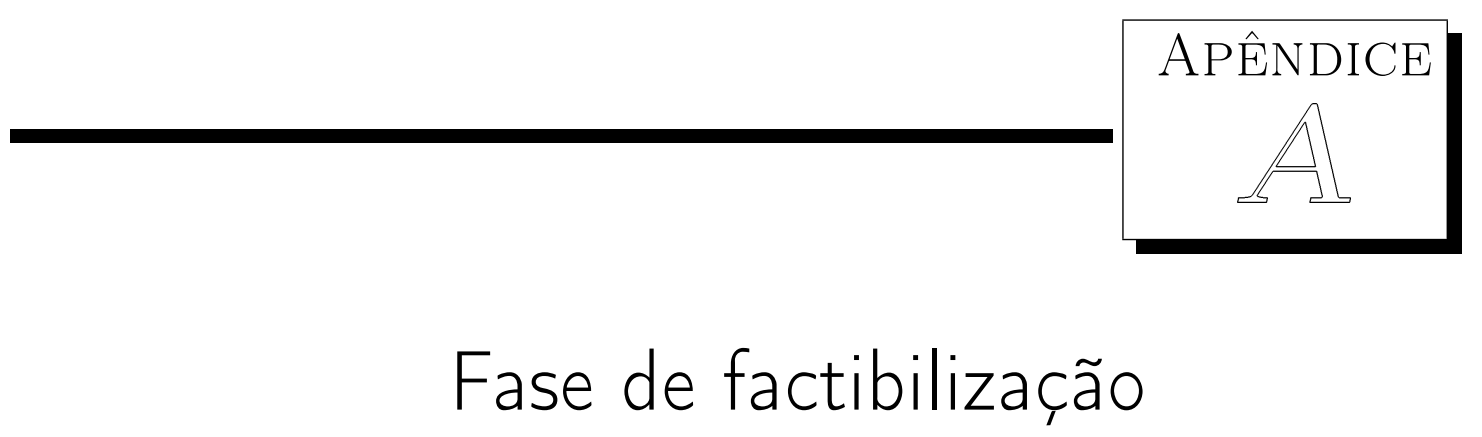

Nos testes realizados com máquinas paralelas, a fase de factibilização da heurística proposta não conseguiu encontrar soluções factíveis para várias instâncias. Devido a isto, recorreu-se a uma rotina mais robusta proposta por Toledo e Armentano (2006). Apesar desta rotina requerer um tempo computacional bem maior, ela conseguiu obter soluções factíveis para várias soluções que não haviam sido encontradas pela fase de factibilização proposta.

\section{A.1 Descrição}

Seja um período $t$ e uma máquina $j$ em que haja violação das restrições de capacidade da máquina $C_{j}$. Para factibilizar tal período e máquina transfira uma certa produção da máquina $j$ no período $t$, para um período que não viole as restrições de atendimento da demanda e/ou para outra máquina. Defina $\Delta(j, t)$ da seguinte forma:

$$
\Delta(j, t)=\sum_{i=1}^{N}\left(b_{i j} x_{i j t}+f_{i j} y_{i j t}\right)-C_{j}
$$

Seja $a^{+}=\max (a, 0)$. Defina a capacidade excedente da máquina $j$ no período $t$ como:

$$
\operatorname{Excesso}(j, t)=\Delta(j, t)^{+}
$$


Seja, $Z_{i j t}$ a quantidade do item $i$ produzida na máquina $j$ que pode ser transferida do período $t$ para um período $s$. Se $s \neq t, Z_{i j t}=x_{i j t}$, se $s>t, Z_{i j t}=\min _{t \leq r \leq s-1}\left\{x_{i j t}, I_{i r}\right\}$. Seja ainda

$$
Q_{i j t}=\frac{\operatorname{Excesso}(j, t)}{b_{i j}} .
$$

O critério de escolha da quantidade $q$ do item $i$ para remover o $\operatorname{Excesso}(j, t)$ transferindo da máquina $j$ do período $t$ para o período $s \neq t$ e/ou para a máquina $k \neq j$ é dado em A.4.

$$
q=\min \left\{Z_{i j t}, Q_{i j t}\right\}
$$

Defina a Variação de Custo(Var) como sendo:

$$
\operatorname{Var}=\frac{q \cdot h_{i}(t-s)+\left(1-y_{i k s}\right) \cdot s_{i k}-\delta_{1} s_{i j}}{\text { solucao/TMN }}
$$

em que

solucao é o valor da solução obtida pela função objetivo, e

$$
\delta_{1}=\left\{\begin{array}{ccc}
1 & \text { se } & q=x_{i j t} \\
0 & \text { se } & q<x_{i j t}
\end{array}\right.
$$

Além disso, é considerada uma Penalidade $(P)$ pela violação da capacidade, cujo cálculo está descrito em A.7.

$$
P=\frac{E x c e s s o \_d e p o i s(j, t)}{C_{j}}+\frac{E x c e s s o \_d e p o i s(k, s)-E x c e s s o \_a n t e s(k, s)}{C_{k}}
$$

em que

$$
\begin{aligned}
& \text { Excesso_depois }=\left[\Delta(j, t)-\left(q \cdot b_{i j}+f_{i j} \delta_{1}\right)\right]^{+} \\
& \text {Excesso_depois }=\left[\Delta(k, s)-\left(q \cdot b_{i k}+\left(1-y_{i k s}\right) f_{i k}\right)\right]^{+} \\
& \text {Excesso_antes }=\Delta(k, s)^{+}
\end{aligned}
$$

O item $i$ a ser transferido, o período $s$ e a planta $k$ destinos são escolhidos usando aqueles que minimizem a Variação de Custo e a violação da capacidade, cujo cálculo está descrito abaixo.

$$
\frac{\operatorname{Var}+\beta \cdot P}{\operatorname{Red}}
$$

em que

$$
\begin{aligned}
& R e d=\frac{q \cdot b_{i j}+f_{i j} \delta_{1}}{C_{j}} \\
& \beta=\text { peso da penalidade. }
\end{aligned}
$$


Desta forma, a fase de factibilização é realizada através da execução de no máximo 15 seqüências de transferências para períodos anteriores e posteriores. Cada seqüência corresponde ao Algoritmo 11:

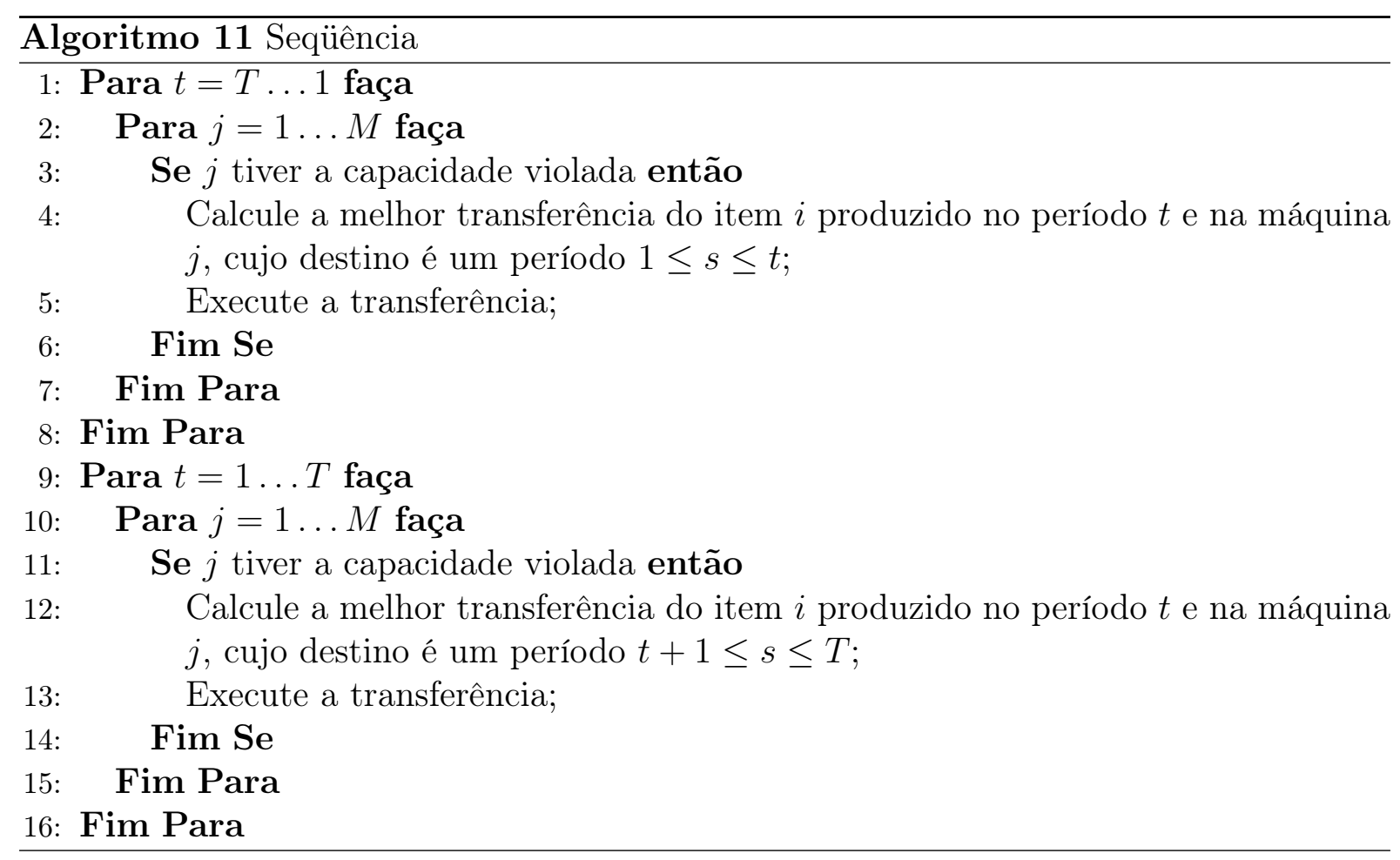

Na primeira seqüência o valor de $\beta$ é 0.15. Este número é dobrado ao final de cada seqüência, pois uma solução factível não foi encontrada. O objetivo de dobrar o valor de $\beta$ é dar maior peso para a violação da capacidade na consideração das transferências. Além disso, a implementação apresenta um controlador de ciclos para evitar que entre em "loop" infinito. 



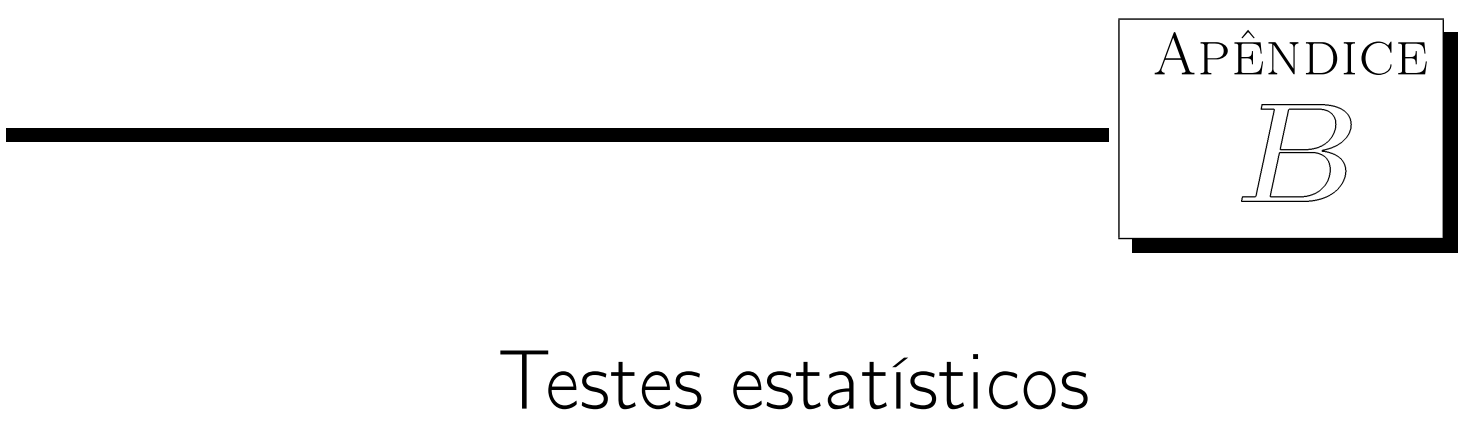

No conjunto de dados referentes aos testes com múltiplas plantas foi usado o teste tStudent pareado. Este teste foi inventado por William Sealy Gosset e é usado para comparar duas amostras de populações dependentes. Isto significa que cada membro da amostra tem uma relação única com outro membro da outra amostra. Para que se possa realizar tal teste é necessário que a diferença dos dados pareados das amostras tenham distribuição normal (Wikipedia e contributors (2007)).

Todos os testes foram executados no software R 2.3.0. Os testes correspondem ao teste t-Student pareado para o de múltiplas plantas com um nível de significância de 0.05. $(\mathrm{gl}=$ graus de liberdade, $\mathrm{t}=$ valor da t-Student $)$

Tabela B.1: Resultados estatísticos de múltiplas plantas para os gaps médios.

\begin{tabular}{l|l|l|l}
\hline Comparações & $\mathrm{t}$ & $\mathrm{gl}$ & $\mathrm{p}$-valor \\
\hline Gheur - LRA $>0$ & 0.74 & 23 & 0.23 \\
GPRheur - LRA $<0$ & -2.31 & 23 & 0.01 \\
GPRheur - Gheur $<0$ & -11.7404 & 23 & 0.00 \\
\hline
\end{tabular}

Para inferir sobre os dados dos testes com máquinas paralelas, foi realizado o chamado Teste de Wilcoxon. Tal teste é não paramétrico e compara duas amostras pareadas, ou seja, é um teste alternativo não paramétrico ao teste t-pareado. O fato de ser não paramétrico faz com que não haja a exigência de algum tipo de distribuição das medidas das amostras. Este teste foi proposto por Frank Wilcoxon (1892-1965) e consiste em calcular a diferença de cada par de medidas e analisar a lista de diferenças (Siegel (1956)). 
Todos os testes foram executados no software R 2.3.0 com um nível de significância de $0.05(\mathrm{~V}=$ valor estatístico).

Tabela B.2: Resultados estatísticos de máquinas paralelas para os gaps médios.

\begin{tabular}{l|l|l|l}
\hline Grupos & Comparações & $\mathrm{V}$ & $\mathrm{p}$-valor \\
\hline \multirow{3}{*}{ Grupo 4 } & LRA-Gheur $<0$ & 0 & 0.0625 \\
& LRA-GPRheur $<0$ & 0 & 0.0625 \\
& GPRHeur-Gheur $<0$ & 0 & 0.0625 \\
\hline \multirow{3}{*}{ Grupo 5 } & LRA-Gheur $<0$ & 0 & 0.0625 \\
& LRA-GPRheur $<0$ & 0 & 0.0625 \\
& GPRHeur-Gheur $<0$ & 0 & 0.0625 \\
\hline \multirow{3}{*}{ Grupo 6 6} & LRA-Gheur $<0$ & 16 & 0.4219 \\
& GPRheur-LRA $<0$ & 14 & 0.3203 \\
& GPRHeur-Gheur $<0$ & 0 & 0.004 \\
\hline
\end{tabular}

Tabela B.3: Resultados estatísticos de máquinas paralelas para os tempos médios.

\begin{tabular}{l|l|c|c}
\hline Grupos & Comparações & $\mathrm{V}$ & $\mathrm{p}$-valor \\
\hline \multirow{3}{*}{ Grupo 4 } & LRA-Gheur $<0$ & 0 & 0.0625 \\
& LRA-GPRheur $<0$ & 0 & 0.0625 \\
& Gheur-GPRheur $<0$ & 0 & 0.0625 \\
\hline \multirow{3}{*}{ Grupo 5 } & LRA-Gheur $<0$ & 0 & 0.0625 \\
& LRA-GPRheur $<0$ & 0 & 0.0625 \\
& Gheur-GPRheur $<0$ & 0 & 0.0625 \\
\hline \multirow{3}{*}{ Grupo 6 6} & LRA-Gheur $<0$ & 8 & 0.097 \\
& LRA-GPRheur $<0$ & 0 & 0.007 \\
& Gheur-GPRheur $<0$ & 0 & 0.004 \\
\hline
\end{tabular}




\section{Referências Bibliográficas}

AgGarwal, A.; PARK, J. K. Improved algorithms for economic lot size problems. Operations Research, v. 41, p. 549-571, 1993.

Armentano, V. A.; Toledo, F. M. B. Dynamic programming algoritms for the parallel machine lot sizing problem. Pesquisa Operacional, v. 17, p. 137-149, 1997.

Atamtürk, A.; Savelsbergh, M. W. P. Integer programming software systems, p. 1-68. 2004.

Bahl, H. C.; Ritzman, L. P.; Gupta, J. N. D. Determining lot sizes and resources requirements: a review. Operations Research, v. 35, p. 329-345, 1987.

Bhatnagar, R.; Chandra, P.; Goyal, S. K. Models for multi-plant coordination. European Journal of Operational Research, v. 67, p. 141-160, 1993.

Bitran, G.; Yanasse, H. Computational complexity of the capacitated lot size problem. Management Science, v. 28, p. 1174-1186, 1982.

Bixby, R.; Fenelon, M.; Gu, Z.; Rothberg, E.; Wunderling, R. Mixed-integer programming: A progress report. Relatório Técnico, 2002.

Brahimi, N.; Dauzere-Peres, S.; Najid, N. M.; Nordli, A. Single item lot sizing problems. European Journal of Operational Research, v. 168, p. 1-16, 2006.

CArreno, J. J. Economic lot scheduling for multiple products on parallel identical processors. Management Science, v. 36, p. 348-358, 1990.

Cornuejols, G.; Fisher, M.; Nemhauser, G. On the uncapacitated location problem. Annals of Discrete Math., v. 1, p. 163-178, 1977.

Crowston, W. B.; F. Glover, G. L. T.; Trawick., J. D. Probabilistic and parametric learning combinations of local job shop scheduling rules. ONR Research memorandum, GSIA, Carnegie Mellon University, Pittsburgh,, 1963.

David Wu, S.; Golbasi, H. Multi-item, multi-facility supply chain planning: models, complexities, and algorithms. Computational Optimization and Applications, v. 28, p. 325-356, 2004. 
Diaby, M.; Bahl, H.; Karwan, M.; Zionts, S. Capacitated lot-sizing and scheduling by lagrangean relaxation. European Journal of Operational Research, v. 59, p. 444-458, 1992a.

Diaby, M.; BAhl, H.; Karwan, M.; Zionts, S. A lagrangean relaxation approach for very-large-scale capacitated lot-sizing. Management Science, v. 59, p. 1329-1340, $1992 b$.

Drexl, A.; Kimms, A. Lot sizing and scheduling - survey and extensions. European Journal of Operational Research, v. 99, p. 221-235, 1997.

Evans, J. R. An efficient implementation of the wagner-whitin algorithm for dynamic lot-sizing. Journal of Operational Management, v. 5, p. 229-235, 1985.

Federgruen, A.; Tzur, M. A simple forward algorithm to solve general dynamic lot sizing models with $\mathrm{n}$ periods in o(nlogn) or o(n) time. Management Science, v. 37, p. 909-925, 1991.

Feo, T.; Resende, M. A probabilistic heuristic for a computationally difficult set covering problem. Operations Research Letters, v. 8, p. 67-71, 1989.

Fleischmann, B. The discrete lot sizing and scheduling problem. Management Science, v. 44, p. 337-348, 1990.

Florian, M.; Lenstra, J. K.; Rinnoy Kan, A. H. G. Deterministic production planning algorithms and complexity. Management Science, v. 26, p. 669-679, 1980.

FrançA, P. M.; Armentano, V. A.; De Toledo, F. M. A network flow model for the capacitated lot-sizing problem. Omega, v. 27, p. 275-284, 1999.

Glover, F.; Laguna, M. Tabu search. Kluwer Academic Publishers, 1997.

GoldBerG, D. Genetic algorithms in search. Addison-Wesley, 1989.

Gopalakrishnan, M.; Ding, K.; Bourjolly, J. M.; Mohan, S. A tabu-search heuristic for the capacitated lot-sizing problem with set-up carryover. Management Science, v. 47, p. 851-863, 2001.

Kaminsky, P.; Simchi-Levi, D. Production and distribution lot sizing in a two stage supply chain. IIE Transactions, v. 35, p. 1065-1075, 2003.

Karimi, B.; Ghomi, S. M. T. F.; Wilson, J. M. The capacitated lot sizing problem: a review of models and algorithms. OMEGA, v. 31, p. 365-378, 2003.

KeLLY, J., B. R.; XU, J. A scatter search-based learning algorithm for neural network training. Journal of Heuristics, v. 2, p. 129-146, 1996.

Kuik, R.; Salomon, M.; Van Wassenhove, L. N. Batching decisions: structure and models. European Journal of Operational Research, v. 75, p. 243-263, 1994.

Laguna, M.; Martí, R. Grasp and path relinking for 2-layer straight line crossing minimization. Informs Journal on Computing, v. 11, n. 1, p. 44-52, 1999. 
Lasdon, L. S.; Teruung, R. C. An efficient algorithm for multi-item scheduling. Operations Research, v. 19, p. 946-969, 1971.

Li, Y.; Pardalos, P.; Resende, M. A greedy randomized adaptive search procedure for the quadratic assignment problem. In: PARdalos, P.; Wolkowicz, H., eds. DIMACS Series on Discrete Mathematics and Theoretical Computer Science, American Mathematical Society, 1994, p. 237-261.

Lozano, S.; Larraneta, J.; Onieva, L. Primal-dual approach to the single level capacitated lot-sizing problem. European Journal of Operational Research, v. 51, p. $354-366,1991$.

Maes, J.; McClain, J. O.; Wassenhove, L. N. V. Multilevel capacitated lotsizing complexity and lp-based heuristics. European Journal of Operational Research, v. 53, p. 131-148, 1991.

Pitsoulis, L. S.; Resende, M. G. Greedy randomized adaptive search procedures. Journal of Global Optimization, v. 6, p. 109-133, 1995.

Resende, M. Computing approximate solutions of the maximum covering problem using grasp. Journal of Heuristics, v. 4, p. 161-171, 1998.

Resende, M.; Ribeiro, C. A grasp for graph planarization. Networks, v. 29, p. 173189, 1997.

Resende, M.; Ribeiro, C. A grasp with path-relinking for private virtual circuit routing. Networks, v. 41, n. 1, p. 104-114, 2003.

Ribeiro, C.; UChOA, E.; Werneck, R. F. A hybrid grasp with perturbations for the steiner problem in graphs. INFORMS Journal of Computing, v. 14, p. 228-246, 2002.

Rochat, Y.; Taillard, . D. Probabilistic diversification and intensification in local search for vehicle routing. Journal of Heuristics, v. 1, p. 147-167, 1995.

Sambasivan, M.; Schimidt, C. P. A solution procedure to solve uncapacitated lot sizing for multi-plant, multi-period problems with inter-plant transfers. Relatório Técnico, 1999.

Sambasivan, M.; Schimidt, C. P. A heuristic procedure for solving multi-plant, multiitem, multi-period capacited lot-sizing problems. Asia Pacific Journal of Operational Research, v. 19, p. 87-105, 2002.

SAmbasivan, M.; YAHYA, S. A lagrangean-based heuristic for multi-plant, multi-item, multi-period capacitated lot-sizing problems with inter-plant transfers. Computers and Operations Research, v. 32, p. 537-555, 2005.

SiEgel, S. Non-parametric statistics for the behavioral sciences. New York, 1956.

SouzA, K. X. S.; Armentano, V. A. Multi-item capacitated lot-sizing by a cross decomposition based algorithm. Annals of Operations Research, v. 50, p. 557-574, 1994. 
Sox, C. R.; GAO, Y. B. The capacitated lot sizing problem with setup carry-over. IEE Transactions, v. 31, p. 173-181, 1999.

Sung, C. A single-product parallel-facilities production-planning model. International Journal of Systems Science, v. 17, p. 983-989, 1986.

Toledo, F. M. B.; Armentano, V. A. A lagrangean-based heuristic for the capacitated lot-sizing problem in parallel machines. European Journal of Operational Research, v. 175, p. 1070-1083, 2006.

Trigeiro, W. W.; Thomas, L. J.; McClain, J. O. Capacitated lot sizing with setup times. Management Science, v. 35, p. 353-366, 1989.

Wagelmans, A.; Van Hoesel, S.; Kolen, A. Economic lot sizing: an o(nlogn) algorithm that runs in linear time in the wagner-whitin case. Operations Research, v. 40, p. $145-156,1992$.

Wagner, H. M.; Whitin, T. M. Dynamic version of the economic lot size mode. Management Science, v. 5, p. 89-96, 1958.

Wikipedia; CONTRIBUtors Student's t-test. Wikipedia, The Free Encyclopedia, 2007.

Wolsey, L. A. Progress with single-item lot-sizing. European Journal of Operational Research, v. 86, p. 395-401, 1995. 